Nutrition counseling

Word Count

Abstract: 223 words

Manuscript: 6,380 words

\title{
Best nutrition counseling practices for the treatment of anorexia nervosa: A Delphi study
}

\section{Anne Mittnacht}

Department of Nutrition at the University of North Carolina at Chapel Hill

\section{Cynthia Bulik, PhD}

Department of Psychiatry and Department of Nutrition at the University of North Carolina at Chapel Hill 
Abstract

Objective: To use Delphi methodology to evaluate the extent to which a panel of eating disorder dietitians concur on parameters related to nutrition counseling for anorexia nervosa (AN). Method: This study involved 21 eating disorder dietitians who: i) were certified registered dietitians (RDs), ii) had specialized in nutritional counseling for eating disorder patients for 5 years or more, and iii) had Internet access at home or work. Over a 10 week period, panelists completed 3 iterative questionnaires. The first questionnaire included 12 open-ended questions regarding nutrition counseling for patients with AN. Subsequent questionnaires contained items that emerged from a content analysis of responses to questions posed in the first questionnaire, and panelists were asked to rank their level of agreement with these items. Results: Consensus was reached for $47(35.3 \%)$ of the 133 items included in the third questionnaire. Panelist comments suggest that some items that did not achieve consensus described techniques that are only appropriate for some patients, which was difficult to capture on the questionnaires. Consensus was also not shown for treatment approaches for which there is little evidence. Discussion: Nutritional intervention for AN has some shared features, but is also individualized. A stronger evidence-base for nutritional counseling interventions for AN would provide clearer guidance and facilitate greater consensus among RDs regarding how to best care for this patient population. 
Best nutrition counseling practices for the treatment of anorexia nervosa:

\section{A Delphi Study}

Anorexia nervosa (AN) exacts substantial psychological, physical, and financial costs from individuals, families, and society. AN has the highest mortality rate of any psychological disorder, ${ }^{1-4}$ with suicide being the leading cause of death. ${ }^{5,6}$ In addition, women with AN who sustain a lower than normal weight are at greater risk of experiencing potentially fatal medical complications (e.g., cardiac arrest). ${ }^{7}$ Furthermore, AN is the third most common chronic illness amongst adolescent females. ${ }^{8,9}$ To avoid these adverse consequences, it is essential that patients with AN receive effective, consistent, evidenced-based care. Because AN has psychological as well as medical and nutritional features, a strong consensus exists within the eating disorder field that a multidisciplinary approach to treatment is associated with the best treatment outcomes (e.g., shorter duration of illness and long term recovery). ${ }^{10}$ Treatment teams are ideally comprised of mental health providers, medical providers, and registered dietitians (RDs). RDs who specialize in eating disorders play a critical role within a treatment team, as they are responsible for developing a renourishment plan, monitoring patterns of weight regain, and helping patients to develop a healthy relationship with food. ${ }^{11-13}$ Accredited dietetics programs provide RDs with the knowledge base necessary to understand the physiological and biochemical effects that nutrients have on the body, and to recommend individualized nutrition plans that are based upon a patient's medical status, physical activity level, food preferences, religious and cultural views, etc. ${ }^{10}$ In addition to these fundamental skills, eating disorders RDs must also develop skills specific to the treatment of eating disorders. 
Because the training required for this specialty is not incorporated into the core curricula of most dietetic programs, it is the position of the American Dietetic Association (now the Academy of Nutrition and Dietetics) that the advanced training necessary for RDs to provide adequate nutrition counseling for patients with eating disorders, "must come from a combination of self-study, continuing education programs and supervision by another experienced RD and/or eating disorder specialist." ${ }^{12}$ Research in the eating disorder field is continuously evolving, so eating disorder practitioners need to update their treatment techniques regularly based on emerging research findings. However, research specific to nutrition interventions for AN is limited. ${ }^{1,11}$ As Marcia Herrin, eating disorder RD of 30+ years and author of Nutrition Counseling in the Treatment of Eating Disorders, explains, "One major problem in the nutrition field is that there is very little published on nutrition techniques in the treatment of eating disorders." Consequently, there may be a lack of consensus on what approaches should be taken by eating disorder RDs when they are working with patients with AN. For example, a review of the literature offers no consensus on how to best restore weight in patients with $\mathrm{AN}$, how to talk about weight restoration with patients, how to address eating disordered thoughts, how to talk about meal planning with patients, how to address a patient who refuses to eat, when to admit a patient to a hospital or inpatient facility, ${ }^{10}$ how to define "recovery" from a nutritional standpoint, and how RDs should address the cognitive and affective facets of the disorder while remaining within the scope of their expertise. ${ }^{15,14}$

The Delphi method has been used in multiple settings as a way for a panel of experts to achieve consensus on topics/issues/definitions within their respective fields. ${ }^{16}$ During a Delphi study, panelists are asked to complete 3-4 rounds of iterative questionnaires. During the first 
round, panelists are either asked to rank their level of agreement with pre-determined statements, or they are asked to respond to open-ended questions. ${ }^{17-19,20}$ If open-ended questions are included in the first round, the study investigators generate summary statements of panelist responses to these questions, and panelists are asked to rank summary statements in the second round. In both scenarios, group responses/rankings are fed back to the panelists and the panelists are asked to re-rank each statement. If consensus has been reached (based on a predetermined criterion), and panelists have rankings that lie outside of the consensus, they are asked to specify their rationale for remaining outside of the consensus.

There are several reasons why the Delphi methodology has advantages over other modes of consensus building (e.g., round table discussions). ${ }^{22}$ First, because Delphi discussions are electronic/web-based, it is easier for experts within a field to participate than it would be if they were meeting for a face-to-face discussion, as they are able to participate without having to travel to a single geographic location. Second, panelists remain anonymous to other members of the panel. This format allows panelists to freely express their opinions without feeling pressure to agree with group members who have a tendency dominate group discussions. ${ }^{17,20,22}$ Third, Delphi questionnaires are often implemented over a period of at least 6 weeks, which provides panelists time to carefully consider discussion topics. ${ }^{17}$

The Delphi methodology has been widely used within the medical field, and within the mental health field as a way to reach a group consensus regarding many topics. Examples of studies that used the Delphi methodology to reach consensus on eating disorder treatment topics include the following: In 2008, Tierney et al. conducted a Delphi study to define "chronic anorexia;"19 in 2010, Williams et al. conducted a Delphi Study that aimed to define "essential 
eating disorder psychotherapeutic competencies;"23 and in 2005, Baker used the Delphi technique to better understand "the varied symptom presentation and psychological issues present" in eating disorder patients who are at different stages of life. ${ }^{24}$

This study used the Delphi methodology to evaluate the extent to which a panel of eating disorder dietitians concur on parameters related to nutrition counseling for AN.

\section{METHODS}

\section{Panelists and Recruitment:}

This study was conducted by investigators at the University of North Carolina at Chapel Hill. The governing Institutional Review Board (IRB) at the University of North Carolina at Chapel Hill reviewed the study protocol and exempted it from further review. Recruitment occurred during the first two weeks of the study. During this time, the principal investigator (PI) distributed email invitations to 45 RDs who were identified as experts within the eating disorder field, in an effort to achieve a minimum of 20 participating panelists. ${ }^{17,25}$ The recruitment email described the study in detail and requested that experts sign an online consent form and complete a brief participant questionnaire if they chose to participate. The participant questionnaire verified that panelists met the inclusion criteria, and also inquired about information regarding professional experiences (e.g., number of patients seen, number of articles/books published, number of speaking engagements, etc.).

Criteria for inclusion in this study required that the experts i) were certified RDs, ii) had specialized in nutritional counseling for eating disorder patients for five years or more, and iii) had Internet access at home or work. ${ }^{22}$ Given that there is no exhaustive list of expert RDs in 
the eating disorders field, experts were identified via an online search of eating disorder RDs who had presented at eating disorder conferences and/or who had authored seminal books, book chapters, and articles that discuss nutritional counseling techniques for the treatment of eating disorders. ${ }^{25}$

There was quasi-anonymity between panelists in this study, as several panelists worked for the same organization and/or were affiliated with the same professional networks. Consequently, it is likely that panelists knew the identity of some or most of the other panelists in the study. ${ }^{22,26,27}$ Responses provided by panelists, however, remained anonymous.

\section{Procedure}

Three rounds of online questionnaires were created using the Qualtrics Research Suite, ${ }^{28}$ and were distributed to a panel 21 experts over the course of 10 weeks. Panelists were given one week to complete each questionnaire, and up to two reminders to complete the survey were sent to panelists during each round in order to minimize attrition.

\section{Round 1}

The first questionnaire was mailed to panelists who signed the consent form, completed the participant questionnaire, and met the inclusion criteria. The first questionnaire included 12 open-ended questions regarding nutritional counseling approaches for patients with AN (Table 1). Panelists were given one week after the recruitment end-date to complete the first questionnaire. 


\section{Round 2}

The $\mathrm{PI}$ and an expert reviewer conducted a content analysis of the 252 panelist responses that were collected with the first questionnaire. A total of 15 categories with 133 corresponding summary statements/items emerged from the analysis and were included in the second questionnaire. Panelists were asked to rank each item using a 5-point, Likert scale that included the following response options: '1' (strongly disagree), '2' (disagree), '3' (don't know/depends), '4' (agree), and '5' (strongly agree). At the end of the questionnaire, panelists were given the opportunity to provide comments regarding any thoughts that arose while completing the questionnaire.

\section{Round 3:}

Rankings that were provided by panelists on the second questionnaire were analyzed using diagnostics in Excel. The categories and items that were included in the second questionnaire were carried over into the third questionnaire. ${ }^{17,21,22,25}$ Beneath each item presented, panelists could see their previous response and a histogram depicting the percentage of panelists who selected each ranking category (Figure 1). The histograms also indicated whether a group consensus had been reached. Consensus was achieved when $\geq 85 \%$ of panelists chose rankings 1 and 2 (showed disagreement) OR rankings 4 and 5 (showed 
agreement) (see Defining Consensus below). On the third questionnaire, panelists were asked to rank each item again. If consensus had been reached on an item, and panelists entered rankings that were outside of the consensus, they were encouraged to specify their rationale for remaining outside of the consensus. Again, at the end of the questionnaire panelists were given the opportunity to provide optional comments.

Insert Figure 1 About Here

\section{Statistical Analysis}

A content analysis was performed on the data that were collected with the first questionnaire. The PI and an expert reviewer coded and arranged panelist responses into categories of common themes that were identified during the analysis, and similar responses were combined into single statements. ${ }^{18-21,26,29}$ The data collected on the second and third questionnaires were analyzed using diagnostics in Excel. Missing data points were not included in the analyses. The percentage of panelists who selected each Likert category was calculated for each item. In addition, the PI re-checked the calculations by hand to verify that they were correct. 


\section{Defining Consensus}

To simplify the reporting process, Likert options were combined into three categories: 1) agreement ("agree" and "strongly agree"), 2) "don't know/ depends", and 3) disagreement ("disagree" and "strongly degree"). Consensus was achieved when $\geq 85 \%$ of panelists showed either agreement or disagreement, ${ }^{23}$ "near consensus" was achieved when $\geq 75 \%$ to $<85 \%$ of panelists showed either agreement or disagreement, and "no consensus" was achieved when $<75 \%$ percent of panelists showed either agreement or disagreement. As there is no agreedupon consensus threshold in the literature, a relatively conservative consensus percentage was chosen to reflect true agreement in the field. ${ }^{17,18,20,26,27}$

\section{RESULTS}

\section{Panelist Response Rate}

Twenty-five (55.6\%) of the 45 experts who were invited to participate in this study completed the participant questionnaire. Four of the 20 experts who chose not to participate in the study emailed the PI to decline participation. One respondent chose not to participate because she does not currently work with AN patients, two respondents missed the response deadline, and one respondent chose not to participate and did not indicate why.

Four of the 25 respondents who filled out the participant questionnaire did not end up participating in the study, as two of these individuals did not meet inclusion criteria (they had fewer than five years of experience specializing in work with eating disorder patients), one chose not to participate because she does not actively counsel patients, and one chose not to 
participate and did not indicate why. The remaining 21 RDs comprised the Delphi panel and completed Rounds 1 through 3.

\section{Panelist Characteristics}

Twenty (95.2 \%) of the panelists were female, and 1 (4.76\%) panelist was male. Panelists had been working as RDs for an average of 21 years (SD 10, range 5-35 years), and had specialized in work with eating disorder patients for an average of 14 years (SD 8, range 5-30 years). Panelists had seen 50 to more than 1000 patients with $A N$ in their careers thus far. Ten panelists (47.6\%) had authored books, book chapters, articles, and/or practice guides that discuss nutrition counseling techniques for the treatment of eating disorders. Seventeen panelists (81.0\%) had presented at eating disorder and/or nutrition conferences. Panelists had worked with AN patients in the following treatment settings: inpatient, 1; residential, 3; partial hospitalization, 2; outpatient, 10; private practice, 17; intensive outpatient, 2; other, 5 (Table 2).

Insert Table 2 About Here

The percentage of panelists who showed agreement, disagreement, and selected "don't know/depends" for the 133 items included in the second and third questionnaires can be found in Tables 3,4, and 5. Percentage ratings for specific resources (e.g., book titles, specific organizations, etc.) that were included under "Topic N. Best resources for eating disorder RDs," 
and under "Topic $\mathrm{O}$. Best resources for eating disorder patients," will not be discussed in the following Results section. However, they are included in Tables 3-5.

\section{Results}

Panelists achieved consensus on 47 (35.3\%) of the 133 items included in the second and third questionnaires (Table 3): consensus was achieved on 35 items in the second round, and on an additional 12 items in the third round. Forty-six of these items showed consensus on agreement and one item showed consensus on disagreement. Panelists nearly achieved consensus on 17 (12.7\%) of the 133 items (Table 4), and did not achieve consensus on 69 (51.9\%) of the 133 items (Table 5).

Insert Tables 3-5 About Here

Items for which consensus was achieved ( $\geq 85 \%$ of panelists selected "strongly agree"/ "agree", or "strongly disagree"/ "disagree"):

Topic A. Patient Goal Setting:

There was unanimous consensus that a good patient goal setting strategy is to determine what a patient needs in order to be medically stabilized. In addition, there was consensus in support of using patient-centered counseling techniques to develop patient goals; 
for example, $95 \%$ of panelists agreed that goals should be based on what patients deem important, $90 \%$ of panelists agreed that when patients first seek treatment, they should work with goals that are modest and achievable so that they can develop a sense of capacity and success, and $95 \%$ of panelists agreed that patients should establish goals that are Specific, Measurable, Achievable, Relevant, Time-bound (SMART).

Topic B. Goal Weights:

A consensus was not shown for any of the items included in this section.

Topic C: Goal weights for children and adolescents with AN:

There was unanimous consensus that goal weights for children and adolescents should be based upon trends on growth charts.

Topic D: Addressing weight goals/ weight changes with patients:

There was unanimous consensus that RDs should make patients aware of the signs of malnutrition (e.g., sleep disturbance, amenorrhea, etc.) that will improve with weight restoration. In addition, $95 \%$ of panelists agreed that RDs should encourage their patients to think about achieving a healthy state rather than a healthy weight.

Topic E: Eating plans for patients:

Ninety-five percent of panelists agreed that an eating plan for patients should be based upon what patients are already consuming and modified for improvement. 
Topic F: Addressing body image and other psychological disorders:

There was unanimous consensus that a RD's role is to help patients work through misbeliefs and distortions regarding food, health, metabolism and weight. Likewise, $89 \%$ of panelists agreed that RDs should encourage patients to identify their own body image distortions, and that they should explain to patients that the weight that is gained after one has been malnourished is not always restored evenly on the body and that over time it will likely redistribute.

Topic G: Applying psychological therapy techniques during nutrition counseling sessions:

Ninety-five percent of panelists agreed that incorporating psychological therapy techniques into nutrition counseling sessions reinforces the skills that patients learn in therapy. Similarly, $85 \%$ of panelists agreed that implementing these techniques helps patients to draw the connection between food behaviors and the deeper psychological issues that they are working through in therapy. That being said, $90 \%$ of panelists agreed that RDs should be properly trained in psychological techniques before implementing them. Panelists only achieved consensus on one item that discussed a specific psychological treatment technique, as $85 \%$ of panelists agreed that eating disorder RDs should implement motivational interviewing (MI) techniques during nutrition counseling sessions. 
Topic H: Involving parents in the treatment of children and adolescents with AN:

There was unanimous consensus that parents should participate in the initial nutrition evaluation appointment with children, and $89 \%$ of the panelists agreed that parents should participate in the initial evaluation appointment with adolescents.

Topic I: Engaging patients when they are resistant to recovery:

Ninety-five percent of panelists agreed that when patients are resistant to recovery, RDs should find out what they are passionate about, what motivates them, what their long-term goals are and then talk about how the eating disorder affects these. Furthermore, $90 \%$ of panelists agreed that RDs should let patients know that they understand what is happening to them (e.g., describe negative health parameters that patients may be experiencing and have not yet discussed).

Topic J: Treatment techniques that explore scientific evidence/ the biological explanation of eating disorders:

There was unanimous consensus that treatment techniques that explore scientific evidence/the biological explanation of eating disorders are beneficial for patients and for parents because pointing out the factors that make one susceptible to eating disorder symptoms (e.g., temperament, comorbid psychological issues, etc.) helps to eliminate feelings of guilt/shame. There was also unanimous consensus that using these techniques is beneficial for parents of children/adolescents with AN, as parents are better able to engage in treatment when they have a clearer understanding of AN. 
Topic K: Educating patients about the medical consequences of AN:

Eighty-five percent of panelists agreed that educating patients about the medical consequences of $\mathrm{AN}$ is beneficial because many of them are not aware of the long-term health effects of the disorder. In addition, $90 \%$ of panelists agreed that educating patients about the medical consequences of $A N$ is recommended because the medical consequences are best treated with nutrition restoration

Topic L: Educating patients about the genetic underpinnings of eating disorders:

Ninety percent of panelists agreed that educating patients about the genetic underpinnings of eating disorders is recommended because it helps to alleviate guilt and shame, as parents and children are often relieved to hear that there is a genetic component. In addition, $85 \%$ of panelists agreed that educating patients about the genetic underpinnings of eating disorders is recommended because it helps patients to accept attributes like perfectionism that may have contributed to the eating disorder and that they cannot change.

Topic M: Treatment approaches for patients who are different ages:

Eighty-five percent of panelists disagreed that treatment approaches do not differ for patients who are different ages because the type of treatment provided to a patient depends more on the history of the illness, family involvement and resources, comorbid diagnoses, etc. than it does on age. On the contrary, $95 \%$ of panelists agreed that treatment approaches do differ for patients who are different ages because the motivators of change are different for different age groups, and because the age of the patient determines growth expectations, the 
impact of altered eating behaviors, the patient's medical risk, and other factors that impact treatment.

Topic N: Best resources for eating disorder RDs:

There was unanimous consensus that the following resources are among the best for eating disorder RDs: eating disorder books and journals, guidance and supervision from more experienced peers (e.g., from other eating disorder dietitians, and from other eating disorder professionals), and counseling strategy workshops (in MI, cognitive behavioral therapy (CBT), acceptance and commitment therapy (ACT), dialectical behavior therapy (DBT), etc.). Likewise, 95\% of panelists agreed that group counseling supervision, eating disorder RD peer groups, and organizations are good resources.

Topic O: Best resources for eating disorder patients:

Ninety-five percent of panelists agreed that books are a good resource for eating disorder patients and for parents of eating disorder patients. Similarly, $95 \%$ of panelists agreed that support groups that are led by professionals are a good resource for eating disorder patients.

Wavering between "don't know" and "depends":

Because none of the Likert options reflected the individualized nature of treatment, it is likely that many panelists selected the Likert option "Don't know/depends," because it reflected the individualized nature of treatment more so than the options that indicated either 
agreement or disagreement. For 58 (67.4\%) of the 86 items that did not show consensus, $\geq 85 \%$ of panelists either agreed with the item or selected "don't know/depends." In addition, for 23 (26.7\%) of the 86 items, $\geq 85 \%$ of panelists either disagreed with the item or selected "don't know/depends." These data indicate that panelists were wavering between either agreement or disagreement, and "don't know/depends" on $94.2 \%$ of the items for which consensus was not achieved. Based on multiple comments that were provided by panelists after the second round, it is clear that, for the most part, when panelists selected "don't know/depends," they intended to select "depends," as one panelist commented, "When I answered, 'Don't know/depends,' I was always answering as 'depends.'” Another panelist commented, "I found myself choosing 'Don't know/depends' very often, it feels like almost all strategies depend on the individual characteristics of the patient/client."

\section{DISCUSSION}

Understanding how specialist dietitians treat individuals is important for both service planning and for refining treatment guidelines. The Delphi methodology used here aimed to explore the extent to which dietitians concurred on various parameters related to the treatment of AN. Despite the fact that the panelists were highly experienced specialist providers, the consensus rate in this study was at best moderate, as panelists only showed $\geq$ $85 \%$ agreement or disagreement on $47(35.3 \%)$ of the 133 items included in the second and third questionnaires. This low consensus rate could reflect reality, suggesting that nutritional practices in the treatment of AN are indeed highly variable. Alternatively, factors related to the nature and format of the questions asked could also have contributed to the low consensus. 


\section{Areas of consensus}

Consensus around agreement was achieved on items that discussed treatment techniques/approaches that can be applied to treatment for mostly any patient with AN. For example, $100 \%$ agreement was shown for the following items that discussed treatment approaches: a) the role of an eating disorder RD is to help patients work through misbeliefs and distortions regarding food, health, metabolism and weight; b) the initial patient goal setting strategy is to determine what a patient needs to be medically stable; c) eating disorder RDs should inform patients of the signs of malnutrition (e.g., sleep disturbance, amenorrhea, headaches, dizziness, irritability) that [may] improve with weight restoration; d) parents of children with AN should participate in the initial nutritional counseling session; e) goal weights for children and adolescents should be based on growth trends on growth charts; and f) treatment techniques that explore scientific evidence are beneficial because they point out factors that make one susceptible to eating disorder symptoms (e.g., genetics, temperament, comorbid psychological issues) which helps to eliminate the guilt/shame that patients and/or parents of patients may feel. In addition, consensus was achieved around the belief that dietitians should encourage patients to think about achieving a healthy state rather than health weight, that they should encourage patients to identify their own body image distortions, and that they should use patient- centered counseling approaches to help patients to establish goals. All of the items that achieved consensus describe treatment approaches that apply to any patient because they broadly focus on the core tenets of treatment for AN and they are worded in such a way that leaves room for clinical judgment/intuition (Table 6). 


\section{Factors influencing low consensus}

Different treatment approaches: It possible that the consensus rate was low because panelists in this study do in fact approach treatment of AN differently. The fact that there are few publications that discuss nutrition in the treatment of eating disorders ${ }^{14}$ would explain why RDs who practice separately from one another have developed different approaches to treatment, as the specialized techniques that are used by eating disorder RDs are acquired through the training they receive from more experienced peers, from their personal experiences/ self-education, from eating disorder books and journals, and/or from the treatment guidelines that are in place at the eating disorder facilities where they work. For example, the field currently lacks an evidence-based food plan, ${ }^{7}$ which may explain why consensus around agreement was not shown for one of the specific eating plans for AN patients (e.g., the Exchange System, United States Department of Agriculture's My Plate, Marcia Herrin's Rule of Threes (RO3s), and/or food logs).

Similarly, while there is evidence in support of the use of psychotherapy techniques during counseling sessions between AN patients and mental health providers, and in support of the use of psychotherapeutic techniques during nutritional counseling sessions in general, ${ }^{30}$ there is no empirical evidence to support the use of these techniques during nutritional counseling sessions with AN patients. Consensus was achieved on the opinion that these 
techniques should be incorporated into sessions with AN patients, and use of these techniques is supported by written opinion in the field. ${ }^{7,13}$ Yet, there was little consensus on items that discussed the manner in which these techniques should be implemented, which suggests that a lack of evidence-based guidelines has resulted in inconsistent implementation of them. For example, panelists expressed conflicting views regarding MI. Two of the items included in the questionnaire discussed MI: the item that stated, “Eating disorder RDs should use MI techniques," achieved consensus, while the item that stated, "RDs should implement MI techniques when patients are resistant to treatment," did not. Panelists did not provide comments that would explain this discrepancy in results; however, a few panelists provided comments that reflected differing views on the use of MI. One panelist commented, "I'm SHOCKED that there is not a consensus on this!! MI is the gold standard for our clients!!," while other panelists commented that $\mathrm{MI}$ techniques are only effective when they are implemented correctly. For example, one panelist commented, "It takes a lot of skill to use MI effectively." Another commented, "What do you consider [MI] techniques?" This panelist's request for more information regarding specific $\mathrm{MI}$ approaches reflects the findings of a 2012 systematic review that explored the effectiveness of $\mathrm{Ml}$ techniques in the treatment of eating disorders, as this review was challenged to determine the efficacy of $\mathrm{MI}$ because many of the reviewed treatment studies did not specify which MI techniques had been utilized. $^{31}$

Panelists also expressed conflicting views regarding implementation of family-based treatment (FBT). In response to the item that stated "Parents of children with AN should participate in FBT at a level that is feasible and appropriate for them," one panelist commented, "You either have to do it or not do it. There can't be a lot of going back and forth about who is 
in charge, or 'sometimes' monitoring meals- I have seen that really fail," while another commented, "Why wouldn't you involve the family?"- both of these sentiments were expressed by other panelists as well.

In addition, while there was consensus on the opinion that RDs should be properly trained in psychotherapeutic techniques before using them [an opinion that is supported by the literature], ${ }^{11,32}$ it is not clear what this training should entail. One panelist commented, "Many of us have been trained through personal experience and working with therapists," and there was unanimous consensus on the opinion that counseling strategy workshops (in MI, CBT, ACT, etc.) are a good resource for eating disorder RDs. However, clarity regarding the exact type or extent of training was not achieved. Conflicting views and unclear training requirements reflect a need for greater consistency in the implementation of and the training for these psychotherapeutic approaches during nutrition counseling sessions for patients with AN.

Limitations to the questionnaire format: It also is possible that the consensus rate was low because it was difficult for panelists to capture the individualized nature of treatment with the Likert options that were provided. While items that discussed treatment approaches that are appropriate for all patients showed the strongest consensus, items that were less universally applicable, did not achieve consensus.

First, consensus was not achieved on items that discussed specific BMI goals for adults. Many of the panelists commented that an individual's weight goal should be based upon the weight when physical and psychological functions are restored, rather than upon an arbitrary number, as one panelist commented, "While I look at BMI, if I have a good weight history, I 
usually give more credence to 'normal' for the individual. I am looking at all health parameters as well as whether weight is stabilizing with normal eating." While a BMI of 20 has been associated with optimal outcomes in patients with $\mathrm{AN},{ }^{10,33}$ the weight at which physical and mental health is restored differs for each individual. ${ }^{7,10,11,34}$ A multifactorial approach to defining weight restoration is discussed in an American Dietetic Association practice paper on Nutrition Intervention in the Treatment of Eating Disorders, which explains that a patient's state of health is reflected in multiple biochemical, behavioral, and cognitive indicators, rather than on weight alone. Thus, it is more appropriate to use goal weight ranges with patients, as this allows for more flexibility/ room for clinical judgment. ${ }^{10}$ Similarly, consensus was not achieved on the opinion that goal weights for adults should be based on resumption of menses (in females). Panelists commented that resumption of menses is not a reliable indicator of health restoration, as one panelist commented, "Sometimes menses returns before a healthy weight is achieved and sometimes a healthy weight is achieved and maintained for months and menses don't return." These opinions are supported by a study that determined that some women with AN may not resume menses when weight is restored because they are in a hypometabolic state. $^{35}$

Second, consensus was not achieved on items that discussed treatment approaches that may not be appropriate for AN patients who are experiencing cognitive impairment as a result of starvation. For example, panelists commented that psychotherapeutic approaches such as CBT and MI may not be appropriate until the brain is re-nourished. The literature supports the opinion that $\mathrm{CBT}$ and $\mathrm{MI}$ may not have the desired impact on patients who are 
malnourished. ${ }^{10,12}$ However, studies do suggest that CBT may improve outcomes in AN patients with a BMI of $\geq 19.5 .^{36}$

Third, panelists did not achieve consensus on agreement for some items that do have an evidence base. For example, consensus was not achieved on the statement that "FBT is the gold standard for patients who live with their parents." Research suggests that FBT is an effective treatment approach for children and adolescents with AN who are under the age of 18 , with a short duration of illness, ${ }^{37}$ however, panelist comments suggest that FBT is not always an appropriate approach. One panelist commented, "There are some families who are not willing to do what it takes to implement FBT." Another panelist commented, "FBT should be presented as an option and then decided upon on an individual basis."

Fourth, consensus was also not achieved on specific strategies that should be used to engage patients when they are resistant to recovery (e.g., involve family members, refer patients to a higher level of care, encourage patients to make a pros/cons list or to write a recovery contract, etc.), or on items that discussed how providing patients with information (e.g., psycho-education on the scientific evidence/biological explanation of eating disorders, on the medical consequences of eating disorders, and on the genetic underpinnings of eating disorders) may affect a patient's motivation to recover. Again, lack of consensus on these items suggests that the Likert options did not reflect the individualized nature of nutritional treatment for $\mathrm{AN}$, as it is difficult to agree or disagree with items that describe approaches that may be appropriate for some patients and inappropriate for others. 


\section{Limitations}

Limitations that were identified by panelists: Multiple panelists identified the Likert category "don't know/depends" as a primary limiting factor in the second and third questionnaire. As discussed above, panelist comments suggest that in most circumstances panelists intended to select "depends" rather than "don't know." One panelist commented, “Combining 'don't know' and 'depends' options confounds the [overall] results, as these are very different options."

Other limitations that were identified by panelists had to do with the wording of items included in the second and third questionnaire. One panelist commented that some items on the questionnaire did not specify whether the approach was specific to children, to adults, or to both populations. Another panelist commented that some of the language included in the items was too vague to agree or disagree with. For example, in response to the item that stated “Eating disorder RDs should be properly trained in psychological techniques before implementing them" this panelist noted, "' Properly trained' is very vague. Do you mean go to school to become a counselor? Take a 2-day workshop? Work under supervision of a skilled clinician, too vague to agree or disagree."

A few items described opinions that are not supported by evidence, which likely influenced the way panelists ranked items. For example in response to the item that stated, "FBT should be used with adult patients who have a support network that will partake in FBT," one panelist commented that this statement is, "stronger than the evidence supports." 
Additional Limitations: Limitations that are common to any study that uses the Delphi methodology include the following: First, panelist attrition is identified as a primary limitation associated with Delphi studies. ${ }^{22,26}$ This study, however, had a strong response rate of $100 \%$ over three rounds, which was a study strength. It is difficult to pinpoint why more than half of the experts recruited to participate chose not to participate, as only a few of these individuals provided a reason for declining participation. Second, the Delphi methodology does not enable panelists to discuss topics. While this element of the technique prevents panelists from being swayed by the opinions of others, it also prevents them from experiencing the benefits that come with intellectual discourse over topics. ${ }^{20}$ Third, some believe that Delphi studies force consensus, because panel members feel as though opinions that differ from opinions that are supported by the majority are incorrect. ${ }^{26}$ Yet, the low consensus rate in this study would suggest otherwise. Also, panelists could only respond to items that were included in the first questionnaire. There may have been other areas, not captured in the initial questionnaire, on which panelists might agree. Lastly, it should be noted that the results from this study should be considered as a reflection of the views of the 21 experts who participated in this study, they are not necessarily generalizable to all dietitians who specialize in the treatment of eating disorders. It is possible that the results would differ had a different group of experts participated in Rounds 1-3. 
Conclusion

This study represents the first known attempt at using the Delphi methodology to achieve consensus amongst a group eating disorder RDs regarding nutritional counseling techniques for the treatment of AN. Consensus was achieved on items that described nutrition counseling approaches that are applicable to all patients with AN, as they were worded in a way that leaves room for consideration of individual needs, and for clinical judgment and flexibility.

On items where consensus was not achieved, panelist comments suggested shared concerns. For example, with regard to weight goals, many panelists commented that BMI goals are not accurate indicators of health restoration. On other items that did not show consensus, panelists shared similar views on why certain approaches are only appropriate for some patients. These shared views/approaches suggests that RDs on this panel are striving to implement the most evidence-informed treatment techniques possible, and that their expert experience with the population has brought them to some similar conclusions regarding best approaches.

Research regarding AN treatment in general is sparse. ${ }^{38}$ Research specifically pertaining to nutritional treatment for AN is even more limited; for example, there is currently no evidence to support the implementation psychotherapeutic techniques during nutrition treatment of AN. ${ }^{7}$ In an effort to make due with the evidence that is available, eating disorder RDs implement psychotherapeutic techniques that have been identified in the research as effective techniques for mental health providers to use when they are working with AN patients. Panelists agree that RDs must be properly trained in these techniques before implementing them; however, it is not clear what this "training" should entail. Despite clear 
efforts to implement evidence-informed techniques, lack of consensus on, and conflicting comments regarding items for which there is little evidence, suggests that the dearth of evidence in this field is keeping RDs from providing the most consistent, effective care possible.

The low consensus rate was likely secondary both to a true lack of consensus in the community as well as to methodological issues within this study. According to panelist comments, in many situations RDs will use clinical judgment to determine which techniques best meet the needs of the patient, as one panelist commented at the end of the second questionnaire, "All of the above stated ideas may at some point be the best course." While it is important to provide individualized care to AN patients, it would be beneficial for practitioners, patients, and parents to have greater consistency in approach. For example, it would be useful for RDs who work in treatment settings where multiple patients are using the same food plan to know which plan is most effective and to implement it.

Because RDs play a critical role in the treatment of patients with $\mathrm{AN}$, it is important that more studies explore approaches that are effective in nutrition counseling for the treatment of AN. A stronger evidence-base would allow RDs to provide better and more consistent care to this patient population and would increase the quality of resources available to eating disorder RDs at all stages of their careers. 
Nutrition counseling

\section{Acknowledgements}

We would like to thank the registered dietitians who participated in this study for their time and for their thoughtful insights. We would also like to thank Dr. Robert Hamer for his advice regarding the statistical analyses used in this study. 


\section{References}

1. Cockfield A, Philpot U. Symposium 8: Feeding size 0: The challenges of anorexia nervosa. Managing anorexia from a dietitian's perspective. Proc Nutr Soc 2009;68:281-288.

2. Neurmarker KJ. Mortality and sudden death in anorexia nervosa. Int J Eat Disord $1997 ; 21: 205-212$.

3. Arcelus J, Mitchell AJ, Wales J, Nielsen S. Mortality rates in patients with anorexia nervosa and other eating disorders. A meta-analysis of 36 Studies. Arch Gen Psychiatry 2011;68:724-731.

4. Crow SJ, Peterson CB, Swanson SA, Raymond NC, Specker S, Eckert ED, et al. Increased mortality in bulimia nervosa and other eating disorders. Am J Psychiatry 2009;166:13421346.

5. Holm-Denoma JM, Witte TK, Gordon KH, Herzog DB, Franko DL, Fichter M, et al. Deaths by suicide among individuals with anorexia as arbiters between competing explanations of the anorexia-suicide link. J Affect Disord 2008;107:231-236.

6. Keel PK, Dorer DJ, Eddy KT, Franko D, Charatan DL, Herzog DB. Predictors of mortality in eating disorders. Arch Gen Psychiatry 2003;60:179-183.

7. Herrin M, Larkin M. Nutrition counseling in the treatment of eating disorders. Second. New York: Routledge;2013.

8. Misra M, Aggarwal A, Miller KK, Almazan C, Worley M, Soyka LA, et al. Effects of Anorexia nervosa on clinical, hematologic, biochemical, and bone density parameters in community-dwelling adolescent girls. Pediatrics 2004;114:1574-1583. 
9. Lucas AR, Beard CM, O'Fallon WM, Kurland LT. 50-year trends in the incidence of anorexia nervosa in Rochester, MN: A population-based study. Am J Psychiatry $1991 ; 148: 917-922$.

10. Waterhous T, Jacob M. Practice paper of the american dietetic association: Nutrition intervention in the treatment of eating disorders. J Am Diet Assoc 2011;1-13.

11. Reiter CS, Graves L. Nutrition therapy for eating disorders. Nutr Clin Pract 2010;25:122136.

12. Henry BW, Ozier AD. Position of the american dietetic association: Nutrition intervention in the treatment of anorexia nervosa, bulimia nervosa, and other eating disorders. J Am Diet Assoc 2006;106:2073-2083.

13. Ozier AD, Henry BW. Position of the american dietetic association: Nutrition intervention in the treatment of eating disorders. J Am Diet Assoc 2011;111:1236-1241.

14. Herrin M, Matsumoto N. How to find a good nutritionist. http://www.psychologytoday.com/blog/eating-disorders-news/201304/how-find-goodnutritionist (accessed 01 Sep 13).

15. Whisenant SL, Smith BA. Eating disorders: Current nutrition therapy and perceived needs in dietetics education and research. J Am Diet Assoc 1995;95:1109-1112.

16. RAND Corporation. Delphi Method. http://www.rand.org/topics/delphi-method.html (accessed 31 Aug 13).

17. Hsu CC, Sandford BA. The Delphi technique: Making sense of consensus. Prac Assess Res Eval 2007;12:1-8.

18. Powell C. The Delphi technique: Myths and realities. J Adv Nurs 2003;41:376-382. 
19. Tierney S, Fox JR. Chronic anorexia nervosa: A Delphi study to explore practitioners' views. Int J Eat Disord 2009;42:62-67.

20. Hasson F, Keeney S, Mckenna H. Research guidelines for the Delphi survey technique. J Adv Nurs 2000;32:1008-1015

21. Heather N, Dallolio E, Hutchings D, White M. Implementing routine screening and brief alcohol intervention in primary health care: A Delphi survey of expert opinion. J Subst Use 2004;9:68-85.

22. Sinha IP, Smyth RL, Williamson PR. Using the Delphi technique to determine which outcomes to measure in clinical trials: Recommendations for the future based on a systematic review of existing studies. PLoS Med 2011;8:1-5.

23. Williams M, Haverkamp BE. Identifying critical competencies for psychotherapeutic practice with eating disordered clients: A Delphi study. Eat Disord 2010;18:91-109.

24. Baker JD. Eating disorders across the life-span: A Delphi study. ETF Collection for Tennessee State University 2005 (Unpublished manuscript)

25. Tolsgaard MG, Todsen T, Sorensen JL, Ringsted C, Lorentzen T, Ottesen B, et al. International multispecialty consensus on how to evaluate ultrasound competence: A Delphi consensus survey. PLoS One 2013;8:1-8.

26. Keeney S, Hasson F, McKenna H. Consulting the oracle: Ten lessons from using the Delphi technique in nursing research. J Adv Nurs 2006;52:205-212.

27. McKenna H. The Delphi technique: A worthwhile research approach for nursing? J Adv Nurs 1994;19:1221-1225. 
28. Qualtrics Research Suite. http://www.qualtrics.com/research-suite/\#enterprise (accessed 12 Jun 13).

29. Forman J, Damschroder L. Qualitative content analysis. In: Jacoby L, Siminoff LA, editors. Empirical methods for bioethics: a primer. San Diego: Elsevier Ltd., 2008, p. 39-62.

30. Sphan JM, Fada RS, Keim KS, Laquatra I, Kellogg M, Jortberg B, et al. State of evidence regarding behavior change theories and strategies in nutrition counseling to facilitate health and food behavior change. J Am Diet Assoc 2010;110:879-891.

31. Macdonald P, Hibbs R, Corfield F, Treasure J. The use of motivational interviewing in eating disorders: A systematic review. Psychiatry Res 2012;200:1-11.

32. King K, Klawitter B. Nutrition counseling therapy: Advanced counseling skills. Third. Baltimore: Lippincott Williams and Wilkins;2007.

33. Lund BC, Hernandez ER, Yates WR, Mitchell JR, McKee PA, Johnson CL. Rate of inpatient weight restoration predicts outcome in anorexia nervosa. Int J Eat Disord 2009;42:301305.

34. Yager J, Devlin M, Halmi K, Herzog D, Mitchell J, Powers P, et al. Practice guidelines for the treatment of patients with eating disorders. Third. American Psychiatric Association 2006;1-128.

35. Sterling WM, Golden NH, Jacobson MS, Ornstein RM, Hertz SM. Metabolic Assessment of menstruating and nonmenstruating normal weight adolescents. Int J Eat Disord 2009;42:658-663. 
Nutrition counseling

36. Carter JC, McFarlane TL, Bewell C, Olmsted MP, Woodside DB, Kaplan AS, Crosby RD. Maintenance treatment for anorexia nervosa: A comparison of cognitive behavior therapy and treatment as usual. Int J Eat Disord 2009;42:202-207.

37. le Grange D, Eisler I. Family interventions in adolescent anorexia nervosa. Child Adolesc Psychiatric Clin N Am 2008;18:159-173.

38. Bulik CM. The challenges of treating anorexia nervosa. Lancet 2013;1-2. 


\section{TABLE 1. Open-ended questions included in first questionnaire}

\begin{tabular}{|c|c|}
\hline 1 & $\begin{array}{l}\text { What do you feel is a good strategy for patient goal setting? How do you } \\
\text { address goal weights with your AN patients? }\end{array}$ \\
\hline 2 & $\begin{array}{l}\text { What eating plan do you use with your AN patients (e.g., the Exchange } \\
\text { System, United States Department of Agriculture's My Plate, Marcia } \\
\text { Herrin's Rule of Threes (RO3s), etc.)? Why? }\end{array}$ \\
\hline 3 & $\begin{array}{l}\text { How do you address body image disturbance issues and other } \\
\text { food/nutrition related issues that are psychological in nature with your } \\
\text { AN patients? }\end{array}$ \\
\hline 4 & $\begin{array}{l}\text { What are your thoughts on eating disorder dietitians applying } \\
\text { psychological therapy techniques such as cognitive behavioral therapy } \\
\text { (CBT), dialectical behavior therapy (DBT), family-based treatment (FBT), } \\
\text { motivational interviewing (MI), and/or acceptance and commitment } \\
\text { therapy ( } \mathrm{ACT} \text { ) when delivering a nutrition intervention? }\end{array}$ \\
\hline 5 & $\begin{array}{l}\text { In what ways do you involve parents of children and adolescents with AN } \\
\text { in treatment? }\end{array}$ \\
\hline 6 & $\begin{array}{l}\text { What approaches do you take to engage patients when they are resistant } \\
\text { to recovery (e.g., struggle to make changes, lie about progress or lack } \\
\text { there-of, etc.)? }\end{array}$ \\
\hline 7 & $\begin{array}{l}\text { What are your thoughts on treatment approaches that incorporate } \\
\text { scientific evidence/ the biological explanation of eating disorders into } \\
\text { dialogue with patients? }\end{array}$ \\
\hline 8 & $\begin{array}{l}\text { What are your thoughts on educating patients about the medical } \\
\text { consequences that long-term AN can have on their bodies (e.g., depletion } \\
\text { of organ tissues and irreversible damage to the brain)? }\end{array}$ \\
\hline
\end{tabular}


Nutrition counseling

TABLE 1. Open-ended questions included in first questionnaire

\begin{tabular}{|ll|}
\hline \hline 9 & What are your thoughts on educating patients about the genetic \\
& underpinnings of eating disorders? \\
10 & In what ways does your treatment approach differ for patients who are in \\
11 & different life stages (e.g., during childhood, adolescence, mid- life, later \\
12 & What do you feel are the best resources for eating disorder dietitians? \\
\end{tabular}


TABLE 2. Baseline characteristics of study participants

Study population $(\mathrm{n}=21)$

For how many years have you worked as a registered

dietitian? (years)

[n (\%)]

$5-10$ years

$5(24)$

$11-20$ years

21-30 years

$9(43)$

31-35 years

$3(14)$

For how many years have you specialized in nutrition counseling for eating disorder patients? (years)

$5-10$ years

$11-20$ years

$5(24)$

21-30

$5(24)$

Do you have an advanced degree in nutrition?

YES

$16(76)$

Masters of Pubic Health

$8(38)$

Other Master's degree

7 (33)

Ed.D

$1(5)$

M.Ed

$1(5)$

DrPH

$1(5)$

PhD

2 (10) 
TABLE 2. Baseline characteristics of study participants

Study population $(n=21)$

NO

How many patients with anorexia nervosa have you seen

in your practice?

Fewer than 100 patients

100-500 patients

500-1000 patients

More than 1000 patients

Other/ unknown

Have you published articles and/or books that discuss

nutrition and eating disorders?

YES

NO

Have you presented at eating disorder and/or nutrition

conferences?

YES

NO

In what kind of treatment settings do you work?

Inpatient

Residential 
Nutrition counseling

39

TABLE 2. Baseline characteristics of study participants

\begin{tabular}{|lr|}
\hline \hline & Study population $(\mathrm{n}=21)$ \\
Partial hospitalization & $2(10)$ \\
Outpatient & $10(48)$ \\
Private practice & $17(81)$ \\
Other (please specify) & $5(24)$ \\
\hline
\end{tabular}


Nutrition counseling

40

\begin{tabular}{|c|c|c|c|c|c|}
\hline & Thematic area & Item & $\begin{array}{l}\text { Did panelists } \\
\text { show } \geq 85 \% \\
\text { Agreement? } \\
\text { [yes/no (\%)] }\end{array}$ & $\begin{array}{c}\text { Did panelists show } \\
\qquad 885 \% \\
\text { Disagreement? } \\
\text { [yes/no (\%)] }\end{array}$ & $\begin{array}{c}\text { Percentage of } \\
\text { panelists who } \\
\text { selected "don't } \\
\text { know"/ "depends" } \\
\text { [\%] }\end{array}$ \\
\hline \multirow[t]{5}{*}{ A. } & Patient goal setting... & & & & \\
\hline & & $\begin{array}{l}\text { A good strategy is to determine what the patient needs to be medically } \\
\text { stabilized }\end{array}$ & yes $(100)$ & no (0) & 0 \\
\hline & & A good strategy is to determine what the patient deems important & yes $(95)$ & no (5) & 0 \\
\hline & & $\begin{array}{l}\text { A good strategy is to begin with modest, achievable goals that will enable } \\
\text { the patient to develop a sense of capacity and success }\end{array}$ & yes $(90)$ & no (5) & 5 \\
\hline & & $\begin{array}{l}\text { A good strategy is to establish goals that are SMART (Specific, Measurable, } \\
\text { Achievable, Relevant, Time-bound) }\end{array}$ & yes (95) & no (0) & 5 \\
\hline \multirow[t]{2}{*}{ B. } & Goal weights for adults... & & & & \\
\hline & & A consensus was not shown for any of the items included in this section. & & & \\
\hline \multirow[t]{2}{*}{ C. } & $\begin{array}{l}\text { Goal weights for children and } \\
\text { adolescents... }\end{array}$ & & & & \\
\hline & & Should be based on growth trends on growth charts & yes (100) & no (0) & 0 \\
\hline D. & $\begin{array}{l}\text { Addressing weight goals/ weight } \\
\text { changes with patients... }\end{array}$ & & & & \\
\hline
\end{tabular}


Nutrition counseling

\begin{tabular}{|c|c|c|c|c|c|}
\hline \multicolumn{2}{|r|}{ Thematic area } & Item & $\begin{array}{l}\text { Did panelists } \\
\text { show } \geq 85 \% \\
\text { Agreement ? } \\
\text { [yes/no (\%)] }\end{array}$ & $\begin{array}{l}\text { Did panelists show } \\
\qquad \geq 85 \% \\
\text { Disagreement? } \\
\text { [yes/no (\%)] }\end{array}$ & $\begin{array}{c}\text { Percentage of } \\
\text { panelists who } \\
\text { selected "don't } \\
\text { know"/ "depends" } \\
{[\%]}\end{array}$ \\
\hline \multirow{4}{*}{ E. } & & $\begin{array}{l}\text { Eating disorder dietitians should make patients aware of the signs of } \\
\text { malnutrition (e.g., sleep disturbance, amenorrhea, headaches, dizziness, } \\
\text { irritability) that will improve with weight restoration }\end{array}$ & yes $(100)$ & no (0) & 0 \\
\hline & & $\begin{array}{l}\text { Eating dietitians should encourage patients to think about achieving a } \\
\text { healthy state rather than a healthy weight }\end{array}$ & yes (95) & no (0) & 5 \\
\hline & Eating plans for patients with AN... & & & & \\
\hline & & $\begin{array}{l}\text { Eating disorder dietitians should take what patients are already consuming } \\
\text { and modify it for improvement }\end{array}$ & yes $(95)$ & no (0) & 5 \\
\hline \multirow[t]{3}{*}{ F. } & $\begin{array}{l}\text { Addressing body image and other } \\
\text { psychological issues... }\end{array}$ & & & & \\
\hline & & $\begin{array}{l}\text { Eating disorder dietitians should explain that weight that is gained after one } \\
\text { has been malnourished is not always restored evenly on the body and that } \\
\text { over time it will likely redistribute }\end{array}$ & yes (89) & no (0) & 11 \\
\hline & & $\begin{array}{l}\text { Eating disorder dietitians should encourage patients to identify their own } \\
\text { distortions }\end{array}$ & yes (89) & no (0) & 11 \\
\hline
\end{tabular}


Nutrition counseling

\begin{tabular}{|c|c|c|c|c|c|}
\hline \multicolumn{2}{|r|}{ Thematic area } & Item & $\begin{array}{l}\text { Did panelists } \\
\text { show } \geq 85 \% \\
\text { Agreement ? } \\
\text { [yes/no (\%)] }\end{array}$ & $\begin{array}{c}\text { Did panelists show } \\
\qquad 885 \% \\
\text { Disagreement? } \\
\text { [yes/no (\%)] }\end{array}$ & $\begin{array}{c}\text { Percentage of } \\
\text { panelists who } \\
\text { selected "don't } \\
\text { know"/ "depends" } \\
{[\%]}\end{array}$ \\
\hline \multirow{5}{*}{ G. } & & $\begin{array}{l}\text { An eating disorder dietitian's role is to help patients work through misbeliefs } \\
\text { and distortions regarding food, health, metabolism, and weight }\end{array}$ & yes (100) & no (0) & 0 \\
\hline & $\begin{array}{l}\text { Applying psychological therapy } \\
\text { techniques during nutrition } \\
\text { counseling sessions... }\end{array}$ & & & & \\
\hline & & $\begin{array}{l}\text { These techniques help patients draw the connection their between food } \\
\text { behaviors and the deeper psychological emotional issues that they are } \\
\text { working through in therapy }\end{array}$ & yes $(85)$ & no (5) & 10 \\
\hline & & $\begin{array}{l}\text { These techniques reinforce skills that patients learn in therapy (e.g., when } \\
\text { addressing a nutritional issue such as eating at a wedding, saying "what DBT } \\
\text { skill might help you with this challenge?") }\end{array}$ & yes $(95)$ & no (0) & 5 \\
\hline & & $\begin{array}{l}\text { Eating disorder dietitians should be properly trained in psychological } \\
\text { techniques before implementing them }\end{array}$ & yes (90) & no (0) & 10 \\
\hline \multirow[b]{2}{*}{$\mathrm{H}$. } & & Eating disorder dietitians should use motivational / interviewing techniques & yes $(85)$ & no (0) & no (15) \\
\hline & $\begin{array}{l}\text { Involving parents in the treatment of } \\
\text { children and adolescents with } A N . .\end{array}$ & & & & \\
\hline
\end{tabular}


Nutrition counseling

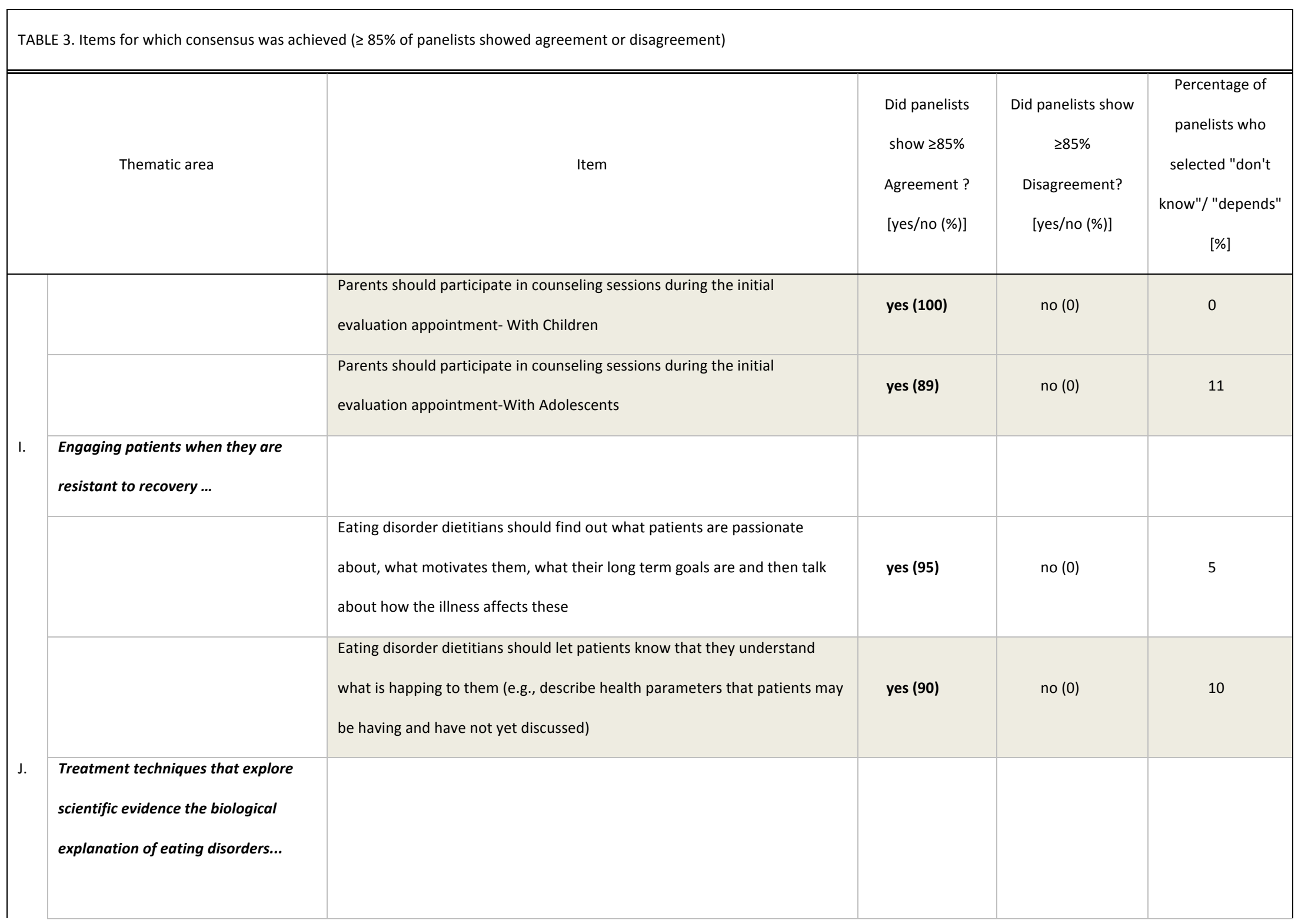


Nutrition counseling

\begin{tabular}{|c|c|c|c|c|c|}
\hline \multicolumn{2}{|r|}{ Thematic area } & Item & $\begin{array}{l}\text { Did panelists } \\
\text { show } \geq 85 \% \\
\text { Agreement ? } \\
\text { [yes/no (\%)] }\end{array}$ & $\begin{array}{c}\text { Did panelists show } \\
\quad \geq 85 \% \\
\text { Disagreement? } \\
\text { [yes/no (\%)] }\end{array}$ & $\begin{array}{c}\text { Percentage of } \\
\text { panelists who } \\
\text { selected "don't } \\
\text { know"/ "depends" } \\
\text { [\%] }\end{array}$ \\
\hline \multirow{5}{*}{ K. } & & $\begin{array}{l}\text { Are beneficial for patients and parents because pointing out factors that } \\
\text { make one susceptible to ED symptoms (e.g., genetics, temperament, } \\
\text { comorbid psychological issues) helps to eliminate feelings of guilt/shame }\end{array}$ & yes $(100)$ & no (0) & 0 \\
\hline & & $\begin{array}{l}\text { Are beneficial for parents because parents are better able to engage in } \\
\text { treatment when they understand eating disorders }\end{array}$ & yes (100) & no (0) & 0 \\
\hline & $\begin{array}{l}\text { Educating patients about the medical } \\
\text { consequences of AN... }\end{array}$ & & & & \\
\hline & & $\begin{array}{l}\text { Is recommended because many patients are not aware of the long-term } \\
\text { health effects of the disease }\end{array}$ & yes (85) & no (0) & 15 \\
\hline & & $\begin{array}{l}\text { Is recommended because these medical consequences are best treated with } \\
\text { nutrition restoration }\end{array}$ & yes $(90)$ & no (0) & 10 \\
\hline \multirow[t]{2}{*}{ L. } & $\begin{array}{l}\text { Educating patients about the genetic } \\
\text { underpinnings of eating disorders... }\end{array}$ & & & & \\
\hline & & $\begin{array}{l}\text { Is recommended because it helps patients to accept attributes like } \\
\text { perfectionism that may have contributed to the eating disorder and that } \\
\text { they cannot change }\end{array}$ & yes (85) & no (10) & 5 \\
\hline
\end{tabular}


Nutrition counseling

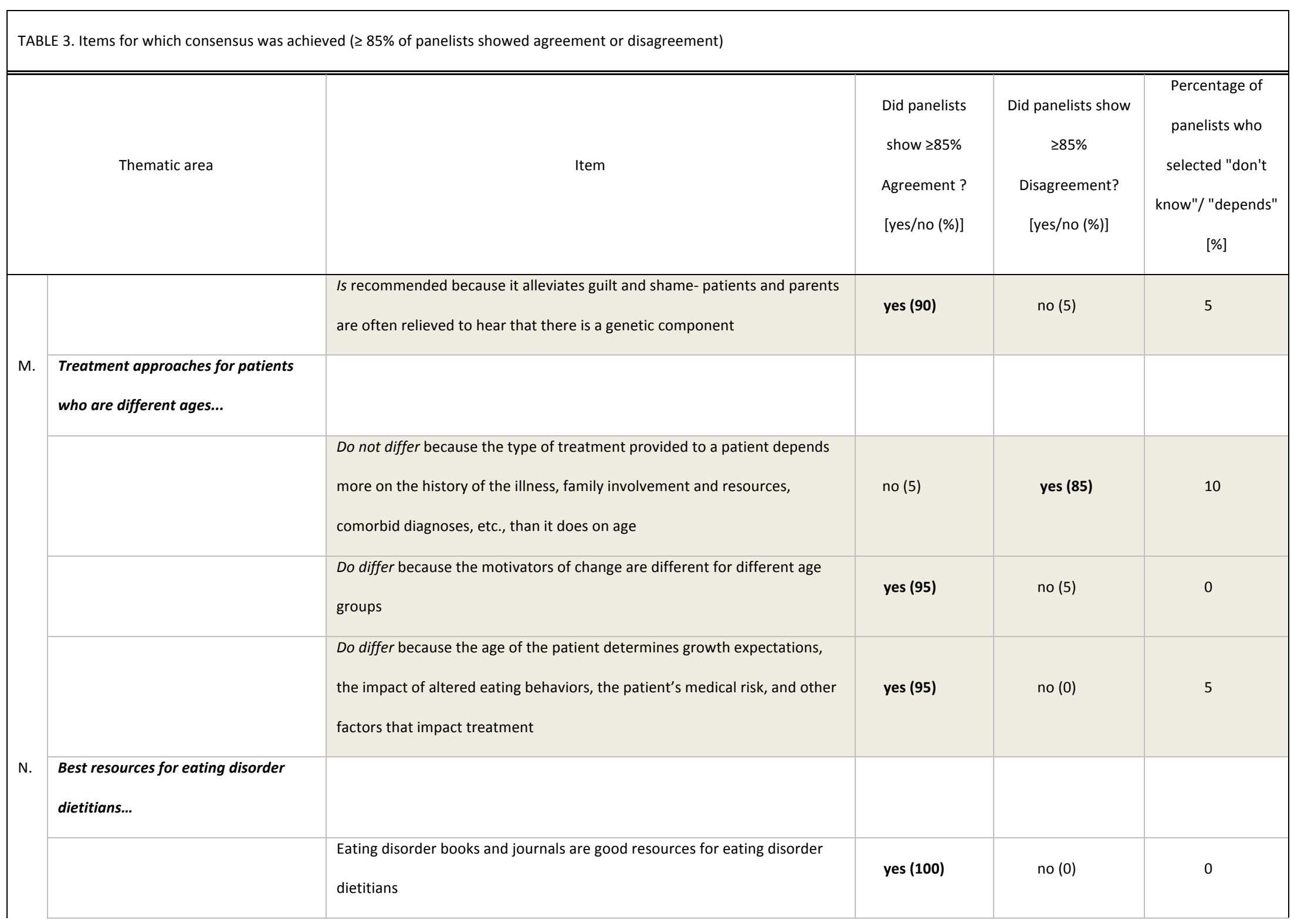


Nutrition counseling

46

\begin{tabular}{|c|c|c|c|c|}
\hline Thematic area & Item & $\begin{array}{l}\text { Did panelists } \\
\text { show } \geq 85 \% \\
\text { Agreement ? } \\
\text { [yes/no (\%)] }\end{array}$ & $\begin{array}{l}\text { Did panelists show } \\
\qquad \geq 85 \% \\
\text { Disagreement? } \\
\text { [yes/no (\%)] }\end{array}$ & $\begin{array}{c}\text { Percentage of } \\
\text { panelists who } \\
\text { selected "don't } \\
\text { know"/ "depends" } \\
\text { [\%] }\end{array}$ \\
\hline & $\begin{array}{l}\text { The best books/journals for eating disorder dietitians include...Child of } \\
\text { Mine: Feeding with Love and Good Sense (Satter) }\end{array}$ & yes $(95)$ & no (0) & 5 \\
\hline & $\begin{array}{l}\text { The best books/journals for eating disorder dietitians include...Nutrition } \\
\text { Counseling in the Treatment of Eating Disorders (Herrin) }\end{array}$ & yes $(85)$ & no (0) & 15 \\
\hline & $\begin{array}{l}\text { The best books/journals for eating disorder dietitians include...The Eating } \\
\text { Disorders Clinical Pocket Guide (Setnick) }\end{array}$ & yes (95) & no (0) & 5 \\
\hline & $\begin{array}{l}\text { The best books/journals for eating disorder dietitians include...the } \\
\text { International Journal of Eating Disorders }\end{array}$ & yes (95) & no (0) & 5 \\
\hline & $\begin{array}{l}\text { Guidance from more experienced peers is a good resource for eating } \\
\text { disorder dietitians }\end{array}$ & yes (100) & no $(0)$ & 0 \\
\hline & The best forms of guidance include ...A mentor an advanced dietitian & yes $(100)$ & no (0) & 0 \\
\hline & The best forms of guidance include .... Individual counseling supervision & yes (100) & no $(0)$ & 0 \\
\hline & The best forms of guidance include...Group counseling supervision & yes $(95)$ & no $(0)$ & 5 \\
\hline & The best forms of guidance include ....ther eating disorder dietitians & yes (100) & no $(0)$ & 0 \\
\hline & $\begin{array}{l}\text { The best forms of guidance include .... Other eating disorder professionals } \\
\text { (therapists, medical professionals, etc.) }\end{array}$ & yes $(100)$ & no (0) & 0 \\
\hline
\end{tabular}


Nutrition counseling

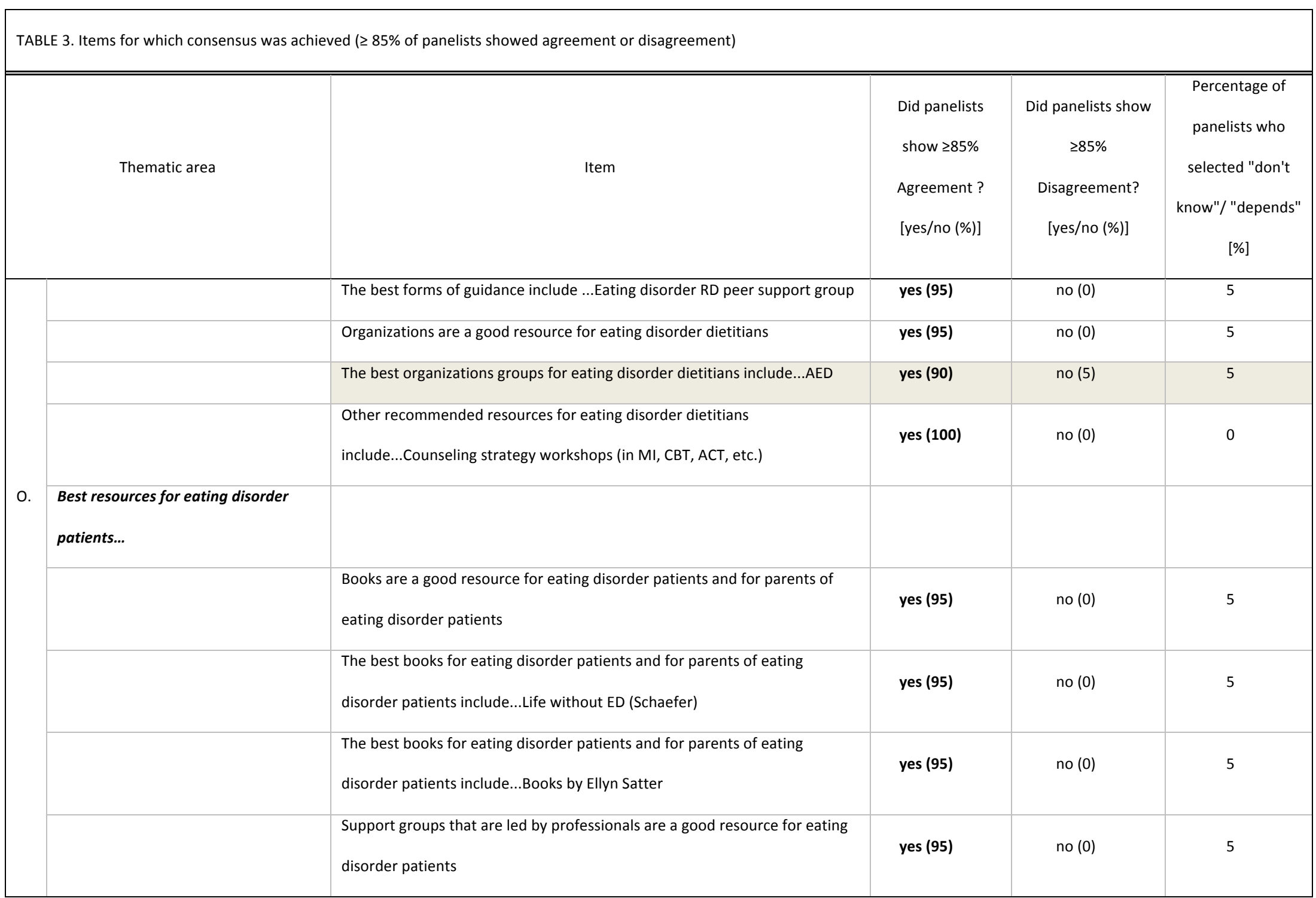

* No highlighting indicates that consensus on this item was achieved after Round 2 and 3. Light gray highlighting indicates that near consensus on this item was achieved after Round 3.) 
Nutrition counseling

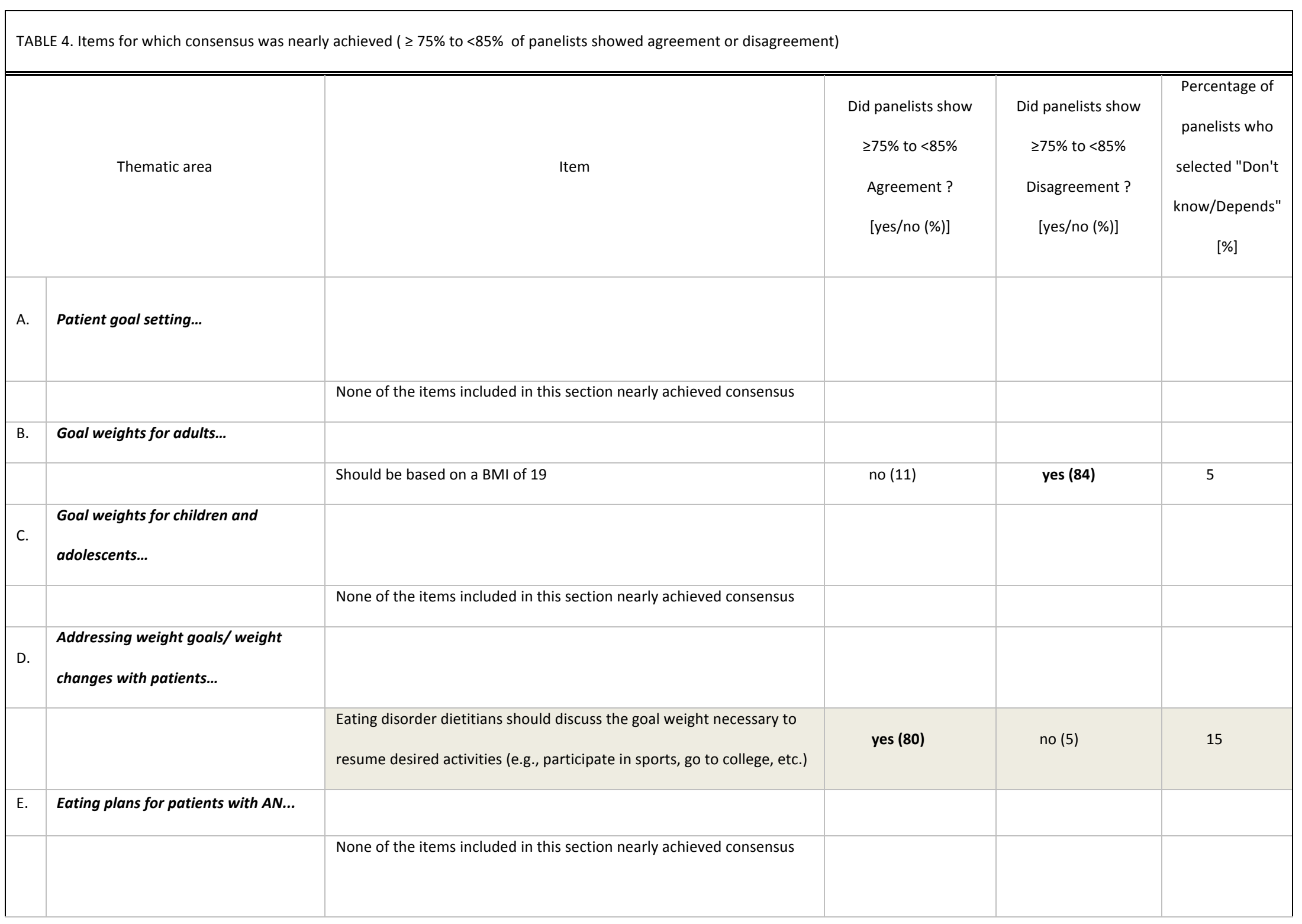


Nutrition counseling

\begin{tabular}{|c|c|c|c|c|c|}
\hline & Thematic area & Item & $\begin{array}{l}\text { Did panelists show } \\
\geq 75 \% \text { to }<85 \% \\
\text { Agreement ? } \\
\text { [yes/no (\%)] }\end{array}$ & $\begin{array}{l}\text { Did panelists show } \\
\begin{array}{c}\geq 75 \% \text { to }<85 \% \\
\text { Disagreement ? } \\
\text { [yes/no (\%)] }\end{array}\end{array}$ & $\begin{array}{l}\text { Percentage of } \\
\text { panelists who } \\
\text { selected "Don't } \\
\text { know/Depends" } \\
\text { [\%] }\end{array}$ \\
\hline \multirow[t]{2}{*}{ F. } & $\begin{array}{l}\text { Addressing body image and other } \\
\text { psychological issues... }\end{array}$ & & & & \\
\hline & & $\begin{array}{l}\text { Eating disorder dietitians should acknowledge body image disturbance } \\
\text { issues as they arise, but they should not address them because they } \\
\text { are outside of a RD's scope of practice }\end{array}$ & no (10) & yes $(\mathbf{8 0})$ & 10 \\
\hline \multirow[t]{2}{*}{ G. } & $\begin{array}{l}\text { Applying psychological therapy } \\
\text { techniques during nutrition } \\
\text { counseling sessions... }\end{array}$ & & & & \\
\hline & & None of the items included in this section nearly achieved consensus & & & \\
\hline \multirow[t]{3}{*}{$\mathrm{H}$. } & $\begin{array}{l}\text { Involving parents in the treatment of } \\
\text { children and adolescents with AN... }\end{array}$ & & & & \\
\hline & & $\begin{array}{l}\text { Parents of children with AN should participate in FBT at a level that is } \\
\text { feasible and appropriate for them }\end{array}$ & yes $(80)$ & no (5) & 15 \\
\hline & & $\begin{array}{l}\text { The patient should be informed of any communication that happens } \\
\text { between the dietitian and the patient's parents so that the patient can } \\
\text { trust that this communication is not happening behind his or her back }\end{array}$ & yes $(80)$ & no (5) & 15 \\
\hline
\end{tabular}


Nutrition counseling

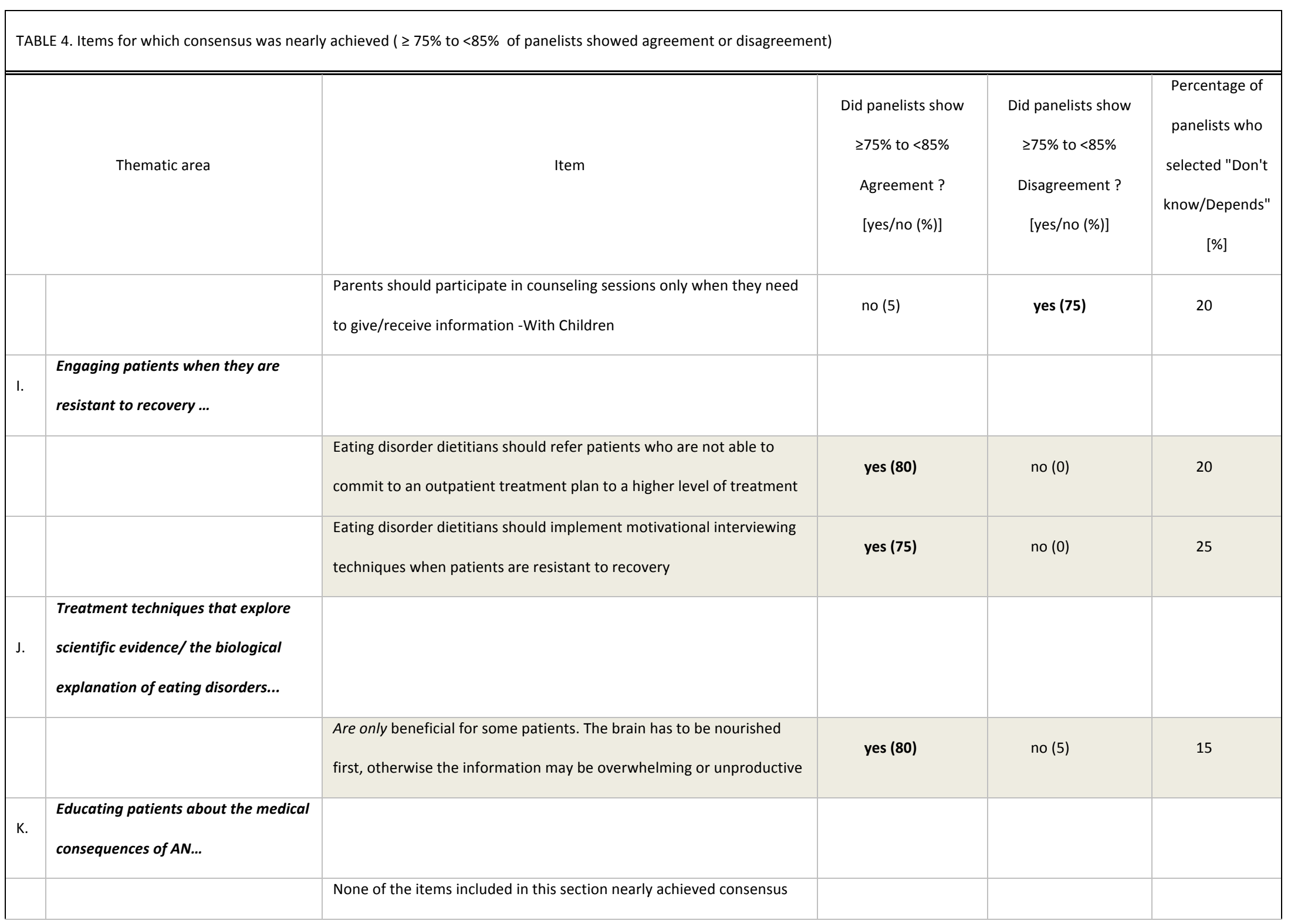


Nutrition counseling

\begin{tabular}{|c|c|c|c|c|c|}
\hline \multicolumn{2}{|r|}{ Thematic area } & Item & $\begin{array}{l}\text { Did panelists show } \\
\begin{array}{c}\geq 75 \% \text { to }<85 \% \\
\text { Agreement ? } \\
\text { [yes/no (\%)] }\end{array}\end{array}$ & $\begin{array}{c}\text { Did panelists show } \\
\geq 75 \% \text { to }<85 \% \\
\text { Disagreement ? } \\
\text { [yes/no }(\%)]\end{array}$ & $\begin{array}{c}\text { Percentage of } \\
\text { panelists who } \\
\text { selected "Don't } \\
\text { know/Depends" } \\
\text { [\%] }\end{array}$ \\
\hline \multirow[t]{2}{*}{ L. } & $\begin{array}{l}\text { Educating patients about the genetic } \\
\text { underpinnings of eating disorders... }\end{array}$ & & & & \\
\hline & & $\begin{array}{l}\text { Is not recommended because dietitians should focus on treatment } \\
\text { rather than on where the eating disorder came from }\end{array}$ & no (5) & yes $(80)$ & 15 \\
\hline \multirow[t]{2}{*}{ M. } & $\begin{array}{l}\text { Treatment approaches for patients } \\
\text { who are different ages... }\end{array}$ & & & & \\
\hline & & None of the items included in this section nearly achieved consensus & & & \\
\hline \multirow[t]{4}{*}{ N. } & $\begin{array}{l}\text { Best resources for eating disorder } \\
\text { dietitians... }\end{array}$ & & & & \\
\hline & & $\begin{array}{l}\text { The best books/journals for eating disorder dietitians include...ADA } \\
\text { Pocket Guide to Eating Disorders (Setnick) }\end{array}$ & yes $(80)$ & no $(0)$ & 20 \\
\hline & & $\begin{array}{l}\text { The best books/journals for eating disorder dietitians include...The } \\
\text { Eating Disorders Sourcebook: A Comprehensive Guide to the Causes, } \\
\text { Treatments, and Prevention of Eating Disorders (Costin) }\end{array}$ & yes $(80)$ & no $(0)$ & 20 \\
\hline & & $\begin{array}{l}\text { The best organizations/groups for eating disorder dietitians } \\
\text { include...NEDA }\end{array}$ & yes $(80)$ & no (10) & 10 \\
\hline
\end{tabular}


Nutrition counseling

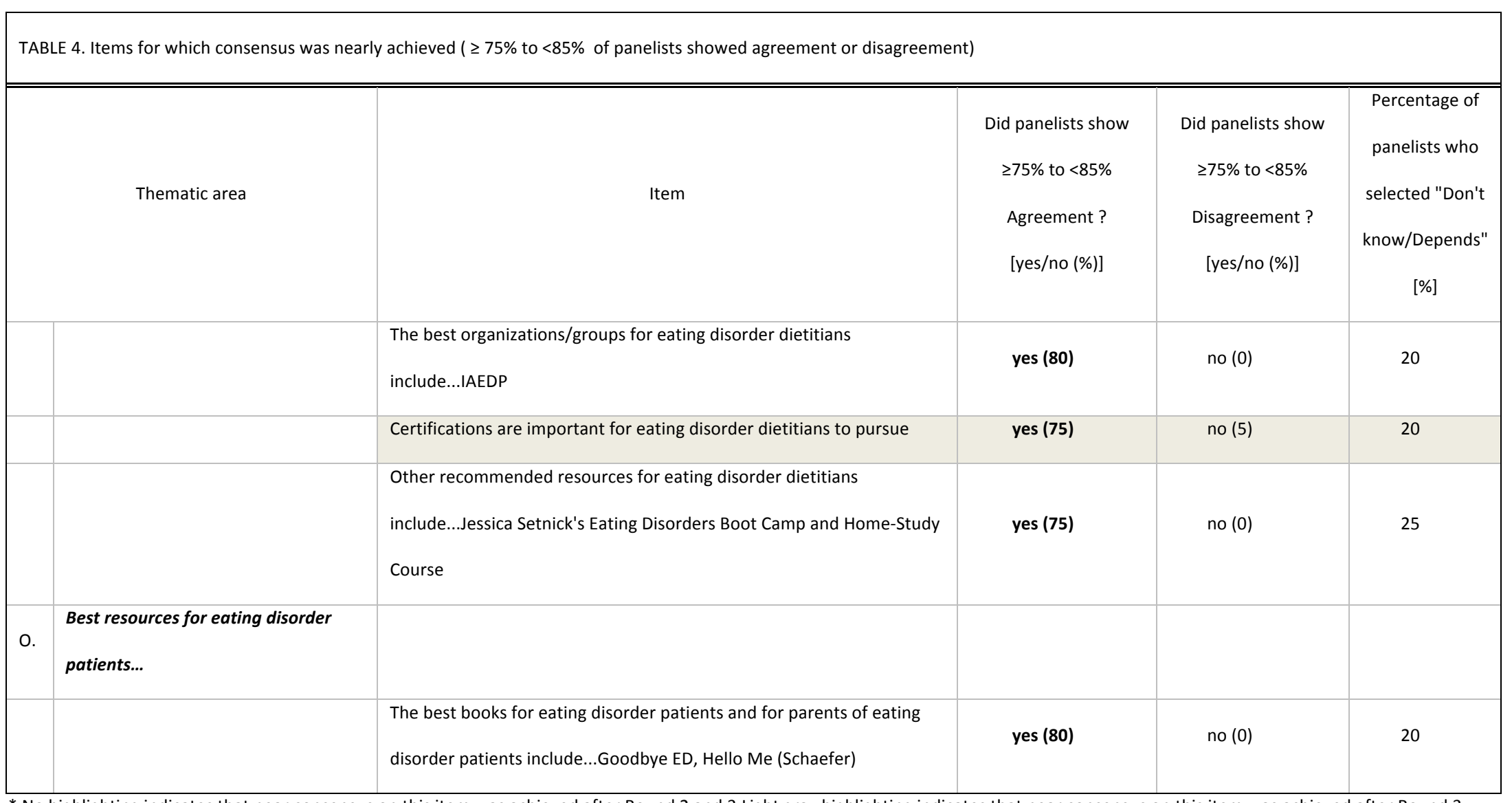

* No highlighting indicates that near consensus on this item was achieved after Round 2 and 3.Light gray highlighting indicates that near consensus on this item was achieved after Round 3 
Nutrition counseling

\begin{tabular}{|c|c|c|c|c|c|}
\hline \multicolumn{2}{|r|}{ Thematic area } & Item & $\begin{array}{c}\% \text { of panelists who } \\
\text { showed agreement } \\
{[\%]}\end{array}$ & $\begin{array}{c}\% \text { of panelists who } \\
\text { showed disagreement } \\
\text { [\%] }\end{array}$ & $\begin{array}{c}\text { \% of panelists } \\
\text { who selected } \\
\text { "Don't know/ } \\
\text { Depends" } \\
{[\%]}\end{array}$ \\
\hline A. & Patient goal setting... & & & & \\
\hline & & $\begin{array}{l}\text { Weight gain is always the initial goal with AN patients because it is } \\
\text { important for bone health and cognitive functioning }\end{array}$ & 47 & 19 & 33 \\
\hline \multirow[t]{7}{*}{ B. } & Goal weights for adults... & & & & \\
\hline & & Should be based on weight history/ past usual weight & 70 & 0 & 30 \\
\hline & & Should be based on the last weight where eating and exercise was normal & 50 & 5 & 45 \\
\hline & & Should be based on resumption of menses (for females) & 21 & 16 & 63 \\
\hline & & Should be based on a BMI of 20 & 10 & 62 & 29 \\
\hline & & Should be based on a BMI of 21 & 5 & 45 & 50 \\
\hline & & A BMI of 22 or higher is necessary for long term recovery & 0 & 25 & 75 \\
\hline \multirow[t]{2}{*}{ C. } & $\begin{array}{l}\text { Goal weights for children and } \\
\text { adolescents... }\end{array}$ & & & & \\
\hline & & $\begin{array}{l}\text { Consensus was either achieved or nearly achieved for all of the items in this } \\
\text { section. }\end{array}$ & & & \\
\hline
\end{tabular}


Nutrition counseling

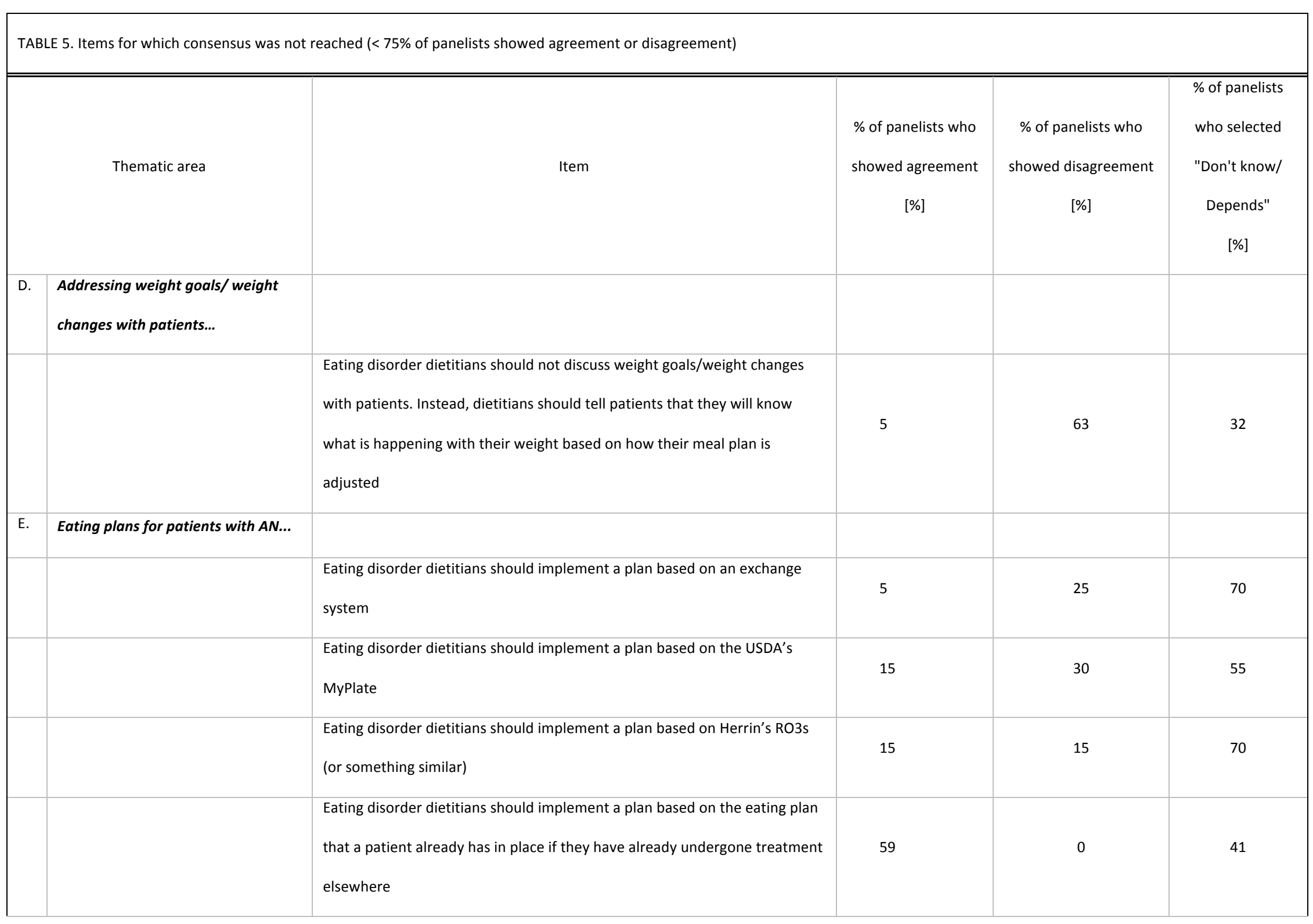


Nutrition counseling

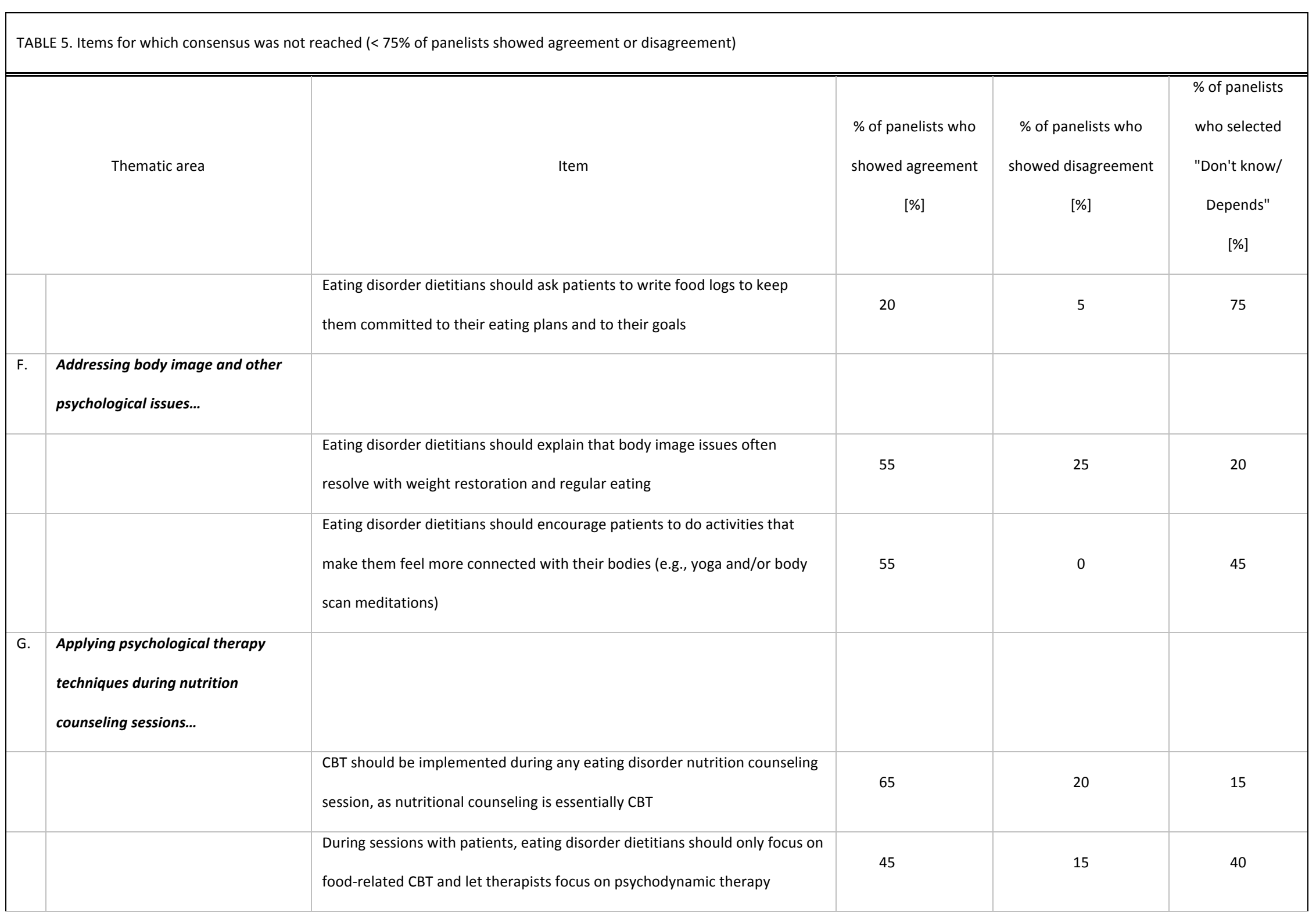


Nutrition counseling

56

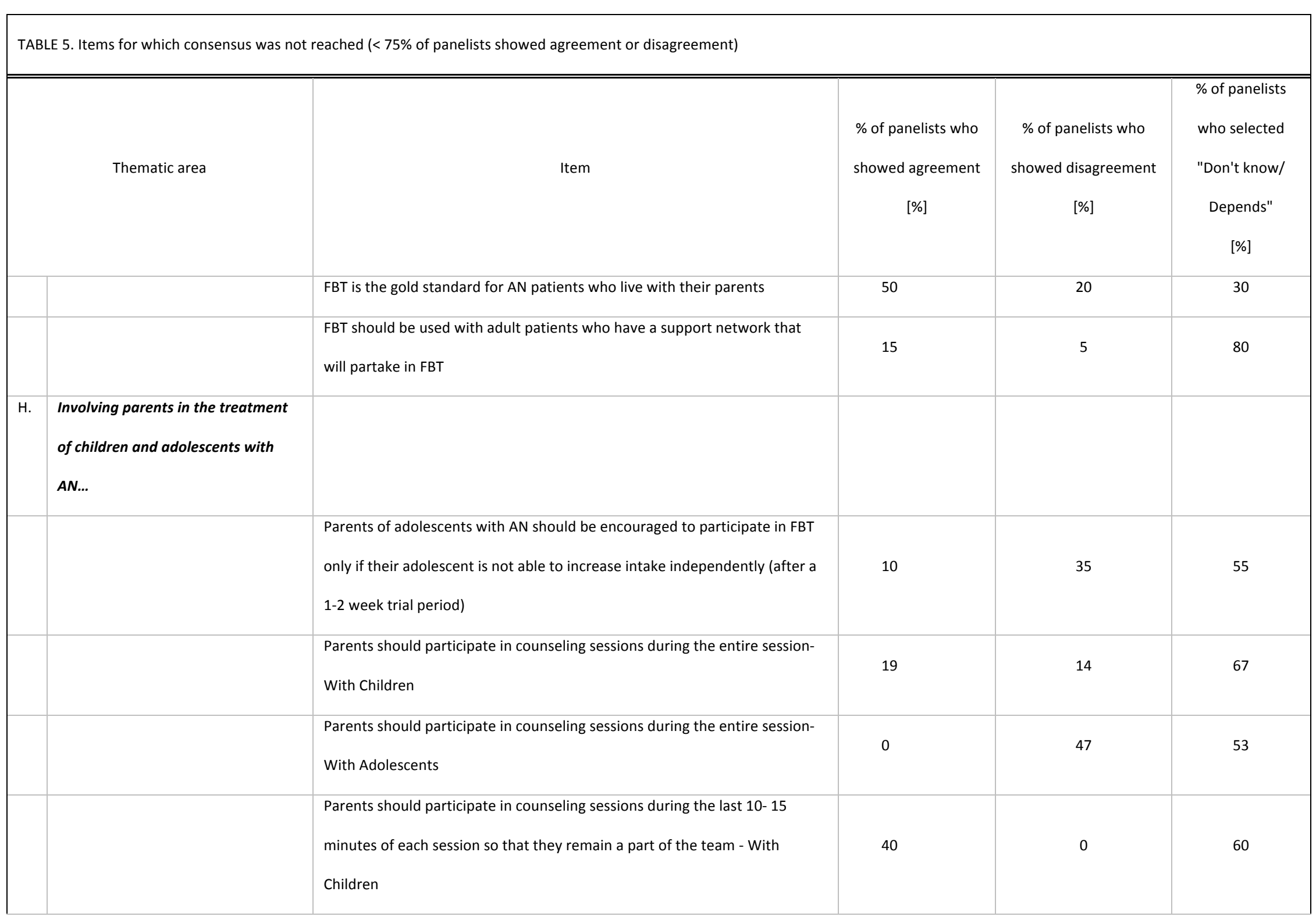


Nutrition counseling

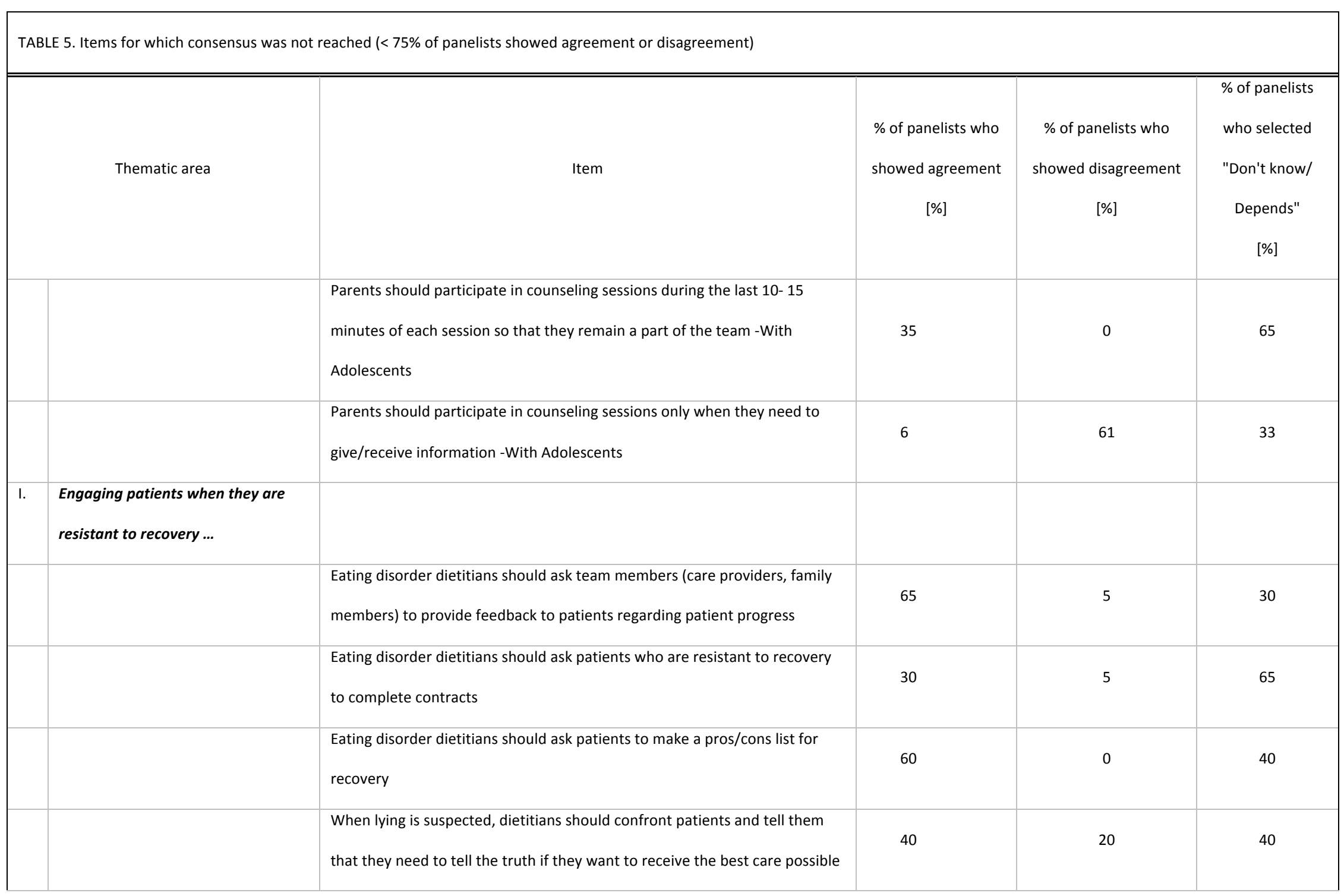


Nutrition counseling

58

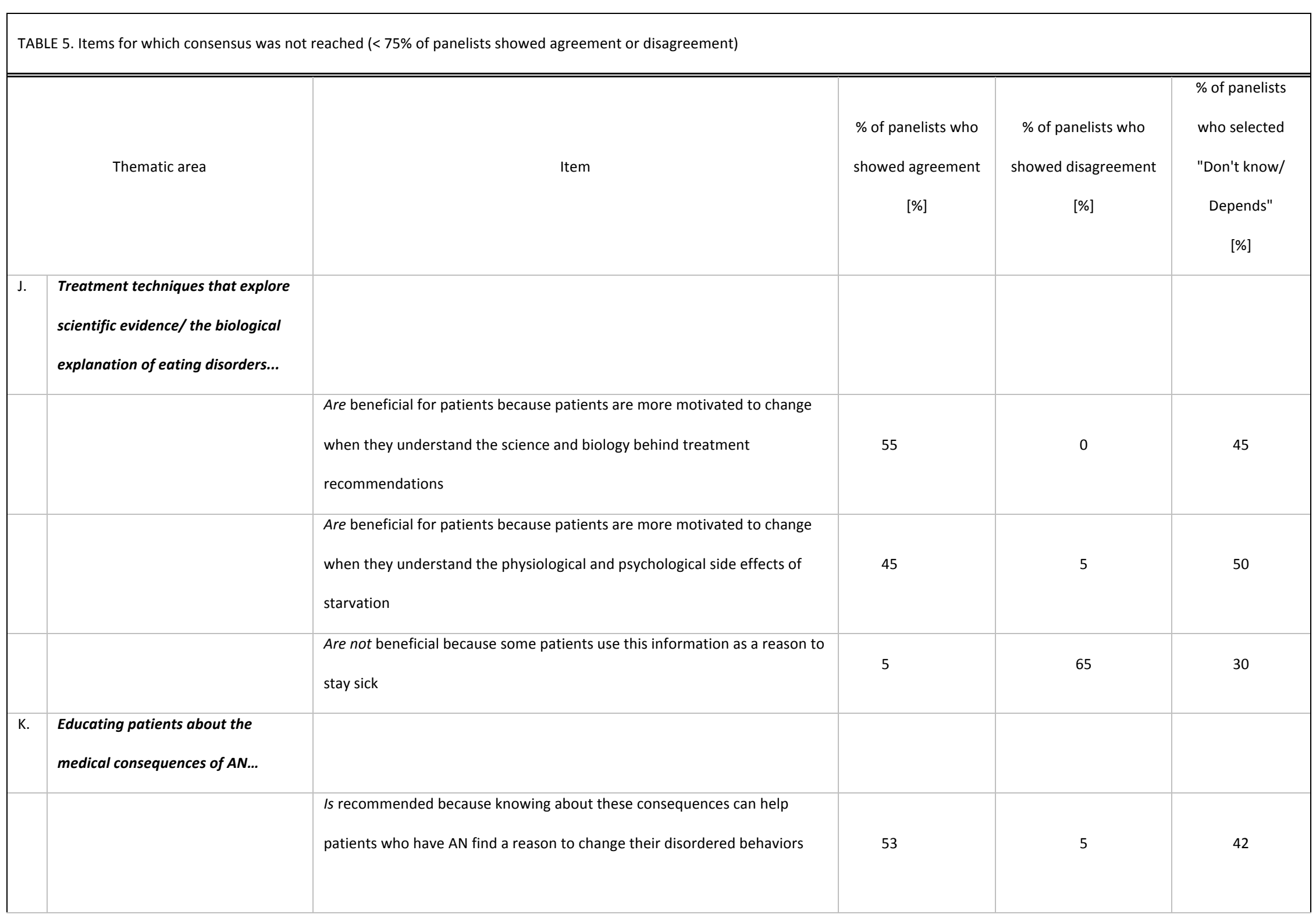


Nutrition counseling

\begin{tabular}{|c|c|c|c|c|c|}
\hline \multirow{4}{*}{\multicolumn{2}{|c|}{ Thematic area }} & \multirow{4}{*}{ Item } & \multirow{4}{*}{$\begin{array}{l}\% \text { of panelists who } \\
\text { showed agreement } \\
\text { [\%] }\end{array}$} & \multirow{4}{*}{$\begin{array}{l}\text { \% of panelists who } \\
\text { showed disagreement } \\
\text { [\%] }\end{array}$} & \multirow{4}{*}{$\begin{array}{c}\text { \% of panelists } \\
\text { who selected } \\
\text { "Don't know/ } \\
\text { Depends" } \\
{[\%]}\end{array}$} \\
\hline & & & & & \\
\hline & & & & & \\
\hline & & & & & \\
\hline & & $\begin{array}{l}\text { Is not recommended for patients younger than age } 14 \text { because they are not } \\
\text { able to conceptualize the future and future consequences }\end{array}$ & 15 & 20 & 65 \\
\hline & & $\begin{array}{l}\text { Is not recommended for patients who are in the early stages of treatment } \\
\text { because these patients don't care- the short term gains of their eating } \\
\text { disorders (e.g., being thin) are most important to them }\end{array}$ & 5 & 35 & 60 \\
\hline & & $\begin{array}{l}\text { Is not recommended if the patient lacks motivation, this information could } \\
\text { be overwhelming or have a negative impact }\end{array}$ & 0 & 25 & 75 \\
\hline \multirow[t]{3}{*}{ L. } & $\begin{array}{l}\text { Educating patients about the } \\
\text { genetic underpinnings of eating } \\
\text { disorders... }\end{array}$ & & & & \\
\hline & & $\begin{array}{l}\text { Is recommended because it helps patients to recognize disordered } \\
\text { behaviors that family members may have modeled as normal. This } \\
\text { awareness can allow patients to let go of these behaviors and normalize } \\
\text { their eating }\end{array}$ & 65 & 15 & 20 \\
\hline & & $\begin{array}{l}\text { Is not recommended because it can be interpreted by parents or patients as } \\
\text { blame }\end{array}$ & 0 & 70 & 30 \\
\hline
\end{tabular}


Nutrition counseling

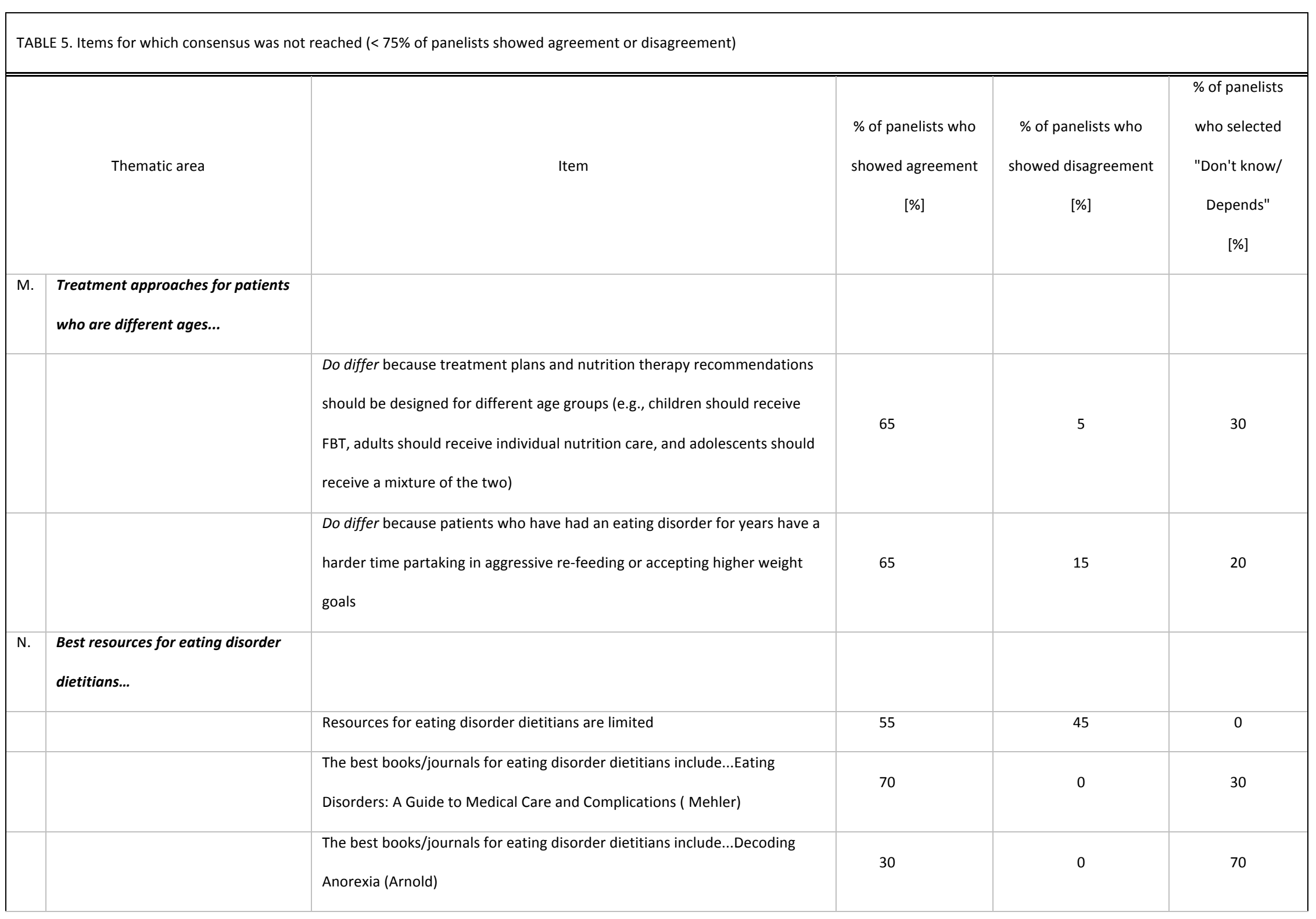


Nutrition counseling

61

\begin{tabular}{|c|c|c|c|c|}
\hline Thematic area & Item & $\begin{array}{l}\text { \% of panelists who } \\
\text { showed agreement } \\
\text { [\%] }\end{array}$ & $\begin{array}{c}\% \text { of panelists who } \\
\text { showed disagreement } \\
\text { [\%] }\end{array}$ & $\begin{array}{c}\text { \% of panelists } \\
\text { who selected } \\
\text { "Don't know/ } \\
\text { Depends" } \\
\text { [\%] }\end{array}$ \\
\hline & $\begin{array}{l}\text { The best books/journals for eating disorder dietitians include...Eating } \\
\text { Disorders: Nutrition Therapy in the Recovery Process (Reiff and Reiff) }\end{array}$ & 74 & 0 & 26 \\
\hline & $\begin{array}{l}\text { The best books/journals for eating disorder dietitians include...Treatment } \\
\text { Manual for Anorexia Nervosa: A Family-Based Approach (Lock and Le } \\
\text { Grange) }\end{array}$ & 70 & 20 & 10 \\
\hline & $\begin{array}{l}\text { The best forms of guidance include ...Patients and families (those in } \\
\text { recovery) }\end{array}$ & 50 & 5 & 45 \\
\hline & $\begin{array}{l}\text { The best organizations/groups for eating disorder dietitians } \\
\text { include...Behavioral Health Nutrition DPG }\end{array}$ & 65 & 10 & 25 \\
\hline & $\begin{array}{l}\text { The best organizations/groups for eating disorder dietitians include... Sports, } \\
\text { CVD, and wellness nutrition DPG }\end{array}$ & 65 & 5 & 30 \\
\hline & The best organizations/groups for eating disorder dietitians include...FEAST & 45 & 10 & 45 \\
\hline & The best organizations/groups for eating disorder dietitians include...ANAD & 40 & 0 & 60 \\
\hline & The best organizations/groups for eating disorder dietitians include...IFEDD & 65 & 5 & 30 \\
\hline & The best certifications for eating disorder dietitians include...IAEDP & 32 & 5 & 63 \\
\hline
\end{tabular}


Nutrition counseling

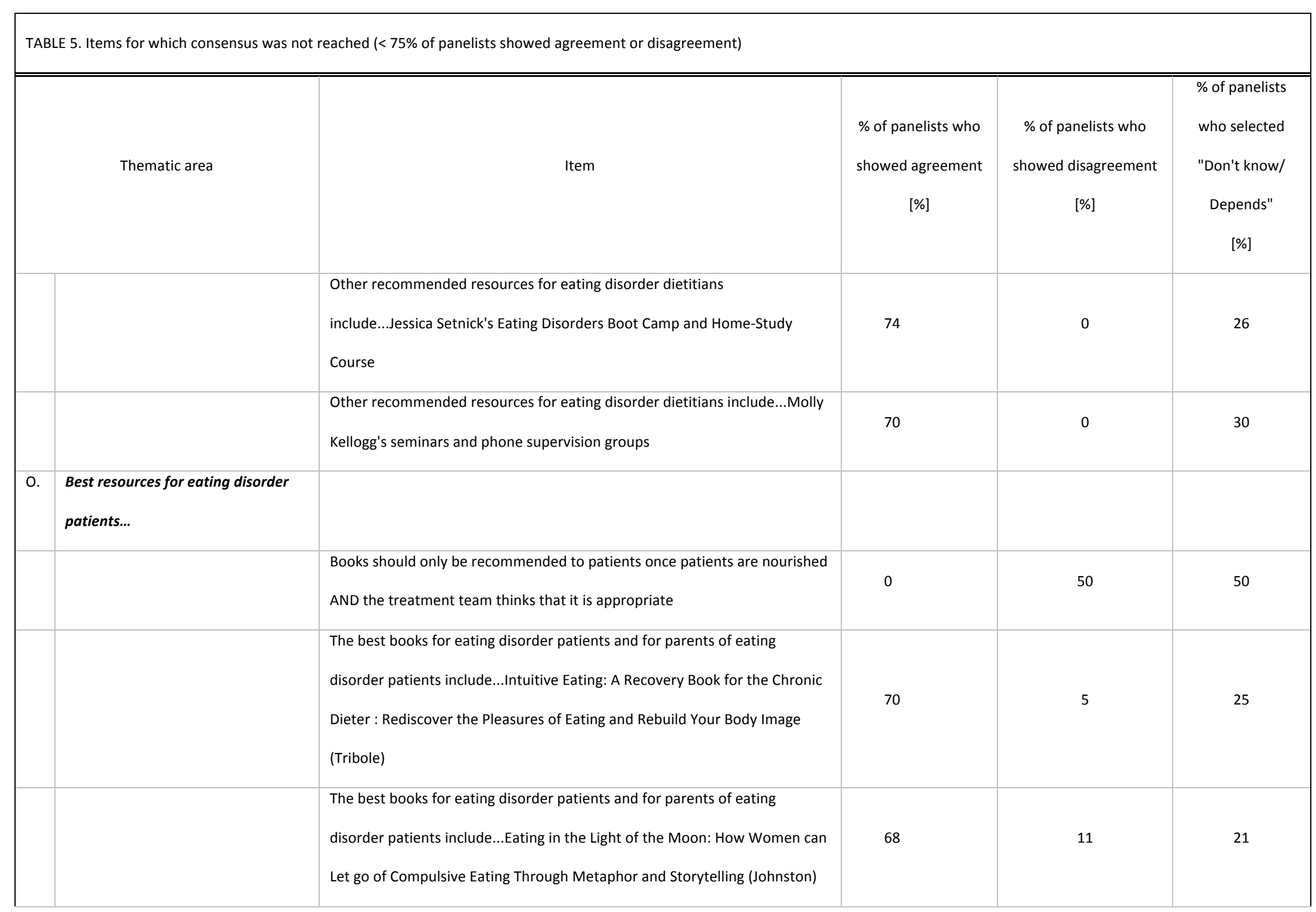


Nutrition counseling

\begin{tabular}{|c|c|c|c|c|}
\hline Thematic area & Item & $\begin{array}{l}\text { \% of panelists who } \\
\text { showed agreement } \\
\text { [\%] }\end{array}$ & $\begin{array}{l}\% \text { of panelists who } \\
\text { showed disagreement } \\
\text { [\%] }\end{array}$ & $\begin{array}{c}\text { of panelists } \\
\text { who selected } \\
\text { "Don't know/ } \\
\text { Depends" } \\
\text { [\%] }\end{array}$ \\
\hline & $\begin{array}{l}\text { The best books for eating disorder patients and for parents of eating } \\
\text { disorder patients include...Skill-based learning for Caring for a Loved one } \\
\text { with an Eating Disorder: The New Maudsley Method (Treasure) }\end{array}$ & 65 & 10 & 25 \\
\hline & $\begin{array}{l}\text { The best books for eating disorder patients and for parents of eating } \\
\text { disorder patients include...The Eating Disorder Sourcebook (Costin) }\end{array}$ & 63 & 0 & 37 \\
\hline & $\begin{array}{l}\text { The best books for eating disorder patients and for parents of eating } \\
\text { disorder patients include... Help Your Teenager Beat an Eating Disorder (Lock } \\
\text { and Le Grange) }\end{array}$ & 55 & 15 & 30 \\
\hline & $\begin{array}{l}\text { The best books for eating disorder patients and for parents of eating } \\
\text { disorder patients include...Decoding Anorexia (Arnold) }\end{array}$ & 21 & 0 & 79 \\
\hline & $\begin{array}{l}\text { The best books for eating disorder patients and for parents of eating } \\
\text { disorder patients include... I'm, Like, So Fat (Neumark-Sztainer) }\end{array}$ & 45 & 0 & 55 \\
\hline & $\begin{array}{l}\text { The best books for eating disorder patients and for parents of eating } \\
\text { disorder patients include...Eating with your Anorexic: How My Child } \\
\text { Recovered Through Family-Based Treatment and Yours Can Too (Collins) }\end{array}$ & 47 & 11 & 42 \\
\hline
\end{tabular}


Nutrition counseling

64

\begin{tabular}{|c|c|c|c|c|}
\hline Thematic area & Item & $\begin{array}{c}\% \text { of panelists who } \\
\text { showed agreement } \\
{[\%]}\end{array}$ & $\begin{array}{c}\% \text { of panelists who } \\
\text { showed disagreement } \\
\text { [\%] }\end{array}$ & $\begin{array}{c}\text { of panelists } \\
\text { who selected } \\
\text { "Don't know/ } \\
\text { Depends" } \\
{[\%]}\end{array}$ \\
\hline & $\begin{array}{l}\text { The best books for eating disorder patients and for parents of eating } \\
\text { disorder patients include...8 Keys to Recovery from an Eating Disorder: } \\
\text { Effective Strategies from Therapeutic Practice and Personal Experience } \\
\text { (Costin) }\end{array}$ & 65 & 0 & 35 \\
\hline & $\begin{array}{l}\text { The best books for eating disorder patients and for parents of eating } \\
\text { disorder patients include...The O.F.F. the Cuff manual (Zucker) }\end{array}$ & 35 & 0 & 65 \\
\hline & $\begin{array}{l}\text { The best books for eating disorder patients and for parents of eating } \\
\text { disorder patients include...Surviving an Eating Disorder (Siegel) }\end{array}$ & 55 & 0 & 45 \\
\hline & $\begin{array}{l}\text { The best books for eating disorder patients and for parents of eating } \\
\text { disorder patients include...The Parent's Guide to Eating Disorders: } \\
\text { Supporting Self-Esteem, Healthy Eating, and Positive Body Image at Home } \\
\text { (Herrin) }\end{array}$ & 60 & 0 & 40 \\
\hline & Pro-recovery websites are a good resource for eating disorder patients & 45 & 5 & 50 \\
\hline & $\begin{array}{l}\text { Patient oriented ED conferences are a good resource for eating disorder } \\
\text { patients }\end{array}$ & 30 & 10 & 60 \\
\hline
\end{tabular}




\section{TABLE 6. Items that achieved consensus/are universally applicable}

\section{Patient goal setting...}

A good strategy is to determine what the patient needs to be medically stabilized

A good strategy is to determine what the patient deems important

A good strategy is to begin with modest, achievable goals that will enable the patient to develop a sense of capacity and success

A good strategy is to establish goals that are SMART (Specific, Measurable, Achievable, Relevant, Time-bound)

\section{Goal weights for adults...}

No consensus achieved on any goal weight question

\section{Goal weights for children and adolescents...}

Should be based on growth trends on growth charts

\section{Addressing weight goals/ weight changes with patients...}

Eating disorder dietitians should make patients aware of the signs of malnutrition (e.g., sleep disturbance, amenorrhea, headaches, dizziness, irritability) that will improve with weight restoration

Eating dietitians should encourage patients to think about achieving a healthy state rather than a healthy weight

\section{Eating plans for patients with AN...}

Eating disorder dietitians should take what patients are already consuming and modify it for improvement

\section{Addressing body image and other psychological issues...}

Eating disorder dietitians should explain that weight that is gained after one has been malnourished is not always restored evenly on the body and that over time it will likely redistribute

Eating disorder dietitians should encourage patients to identify their own distortions

An eating disorder dietitian's role is to help patients work through misbeliefs and distortions regarding food, health, metabolism, and weight

\section{Applying psychological therapy techniques during nutrition counseling sessions...}

These techniques help patients draw the connection their between food behaviors and the deeper psychological emotional 


\section{TABLE 6. Items that achieved consensus/are universally applicable}

issues that they are working through in therapy

These techniques reinforce skills that patients learn in therapy (e.g., when addressing a nutritional issue such as eating at a wedding, saying "what DBT skill might help you with this challenge?")

Eating disorder dietitians should be properly trained in psychological techniques before implementing them

Eating disorder dietitians should use motivational / interviewing techniques

Involving parents in the treatment of children and adolescents with AN...

Parents should participate in counseling sessions during the initial evaluation appointment- With Children

Parents should participate in counseling sessions during the initial evaluation appointment-With Adolescents

Engaging patients when they are resistant to recovery ...

Eating disorder dietitians should find out what patients are passionate about, what motivates them, what their long term goals are and then talk about how the illness affects these

Eating disorder dietitians should let patients know that they understand what is happing to them (e.g., describe health parameters that patients may be having and have not yet discussed)

Treatment techniques that explore scientific evidence the biological explanation of eating disorders...

Are beneficial for patients and parents because pointing out factors that make one susceptible to ED symptoms (e.g., genetics, temperament, comorbid psychological issues) helps to eliminate feelings of guilt/shame

Are beneficial for parents because parents are better able to engage in treatment when they understand eating disorders

\section{Educating patients about the medical consequences of AN...}

Is recommended because many patients are not aware of the long-term health effects of the disease

Is recommended because these medical consequences are best treated with nutrition restoration

\section{Educating patients about the genetic underpinnings of eating disorders...}

Is recommended because it helps patients to accept attributes like perfectionism that may have contributed to the eating disorder and that they cannot change 


\section{TABLE 6. Items that achieved consensus/are universally applicable}

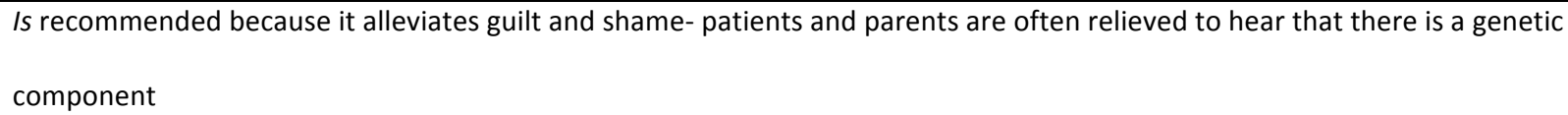

\section{Treatment approaches for patients who are different ages...}

Do not differ because the type of treatment provided to a patient depends more on the history of the illness, family involvement and resources, comorbid diagnoses, etc., than it does on age

Do differ because the motivators of change are different for different age groups

Do differ because the age of the patient determines growth expectations, the impact of altered eating behaviors, the patient's medical risk, and other factors that impact treatment

\section{Best resources for eating disorder dietitians...}

Eating disorder books and journals are good resources for eating disorder dietitians

The best books/journals for eating disorder dietitians include...Child of Mine: Feeding with Love and Good Sense (Satter)

The best books/journals for eating disorder dietitians include...-Nutrition Counseling in the Treatment of Eating Disorders

(Herrin)

The best books/journals for eating disorder dietitians include...The Eating Disorders Clinical Pocket Guide (Setnick)

The best books/journals for eating disorder dietitians include...the International Journal of Eating Disorders

Guidance from more experienced peers is a good resource for eating disorder dietitians

The best forms of guidance include ...A mentor an advanced dietitian

The best forms of guidance include ...Individual counseling supervision

The best forms of guidance include...Group counseling supervision

The best forms of guidance include ...Other eating disorder dietitians

The best forms of guidance include ... Other eating disorder professionals (therapists, medical professionals, etc.)

The best forms of guidance include ...Eating disorder RD peer support group

Organizations are a good resource for eating disorder dietitians

The best organizations groups for eating disorder dietitians include...AED

Other recommended resources for eating disorder dietitians include...Counseling strategy workshops (in MI, CBT, ACT, etc.) 
Nutrition counseling

68

TABLE 6. Items that achieved consensus/are universally applicable

Best resources for eating disorder patients...

Books are a good resource for eating disorder patients and for parents of eating disorder patients

The best books for eating disorder patients and for parents of eating disorder patients include...Life without ED (Schaefer)

The best books for eating disorder patients and for parents of eating disorder patients include...Books by Ellyn Satter

Support groups that are led by professionals are a good resource for eating disorder patients 
Nutrition counseling

FIGURE 1: Screen shot of item included in the third questionnaire

Eating dietitians should encourage patients to think about achieving a healthy state rather than a healthy weight

Panel response: $\geq 85 \%$ agree or strongly agree (Consensus achieved)

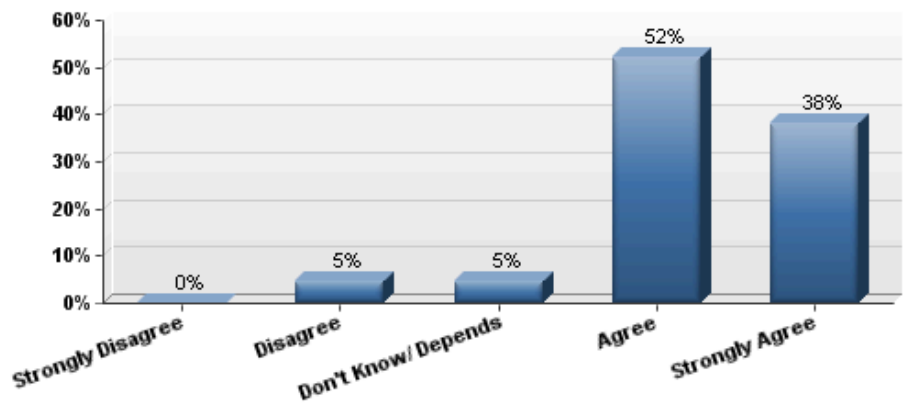

Your last response:

Please indicate your current response below:

Strongly Disagree

Disagree

Don't Know/ Depends

Agree

Strongly Agree

$\bigcirc$

$\bigcirc$

$\bigcirc$ 